\title{
3. Zur Entwicklung des Gebäudes und der Ausstattung der Biologischen Anstalt auf Helgoland
}

\subsection{Bau, Erweiterung, Umbau und Neubau der Gebäude}

Das erste Gebäude der Königlichen Biologischen Anstalt auf Helgoland, ein bescheidener Bau im Helgoländer Stil, befand sich zwischen Kaiserlicher Post und "Villa Franz". Das Haus hatte drei Stockwerke, die Grundfläche betrug 82 Quadratmeter. Die künftigen Nutzer konnten auf die Innengestaltung ihrer Arbeitsstätte Einfluß nehmen. Erste Vorstellungen über den Innenausbau des Stationsgebäudes entwickelte ein Kuratorium, dem u. a. der spätere Kustos Clemens Hartlaub angehörte.

Angaben darüber, wie das Gebäude nach Fertigstellung von innen aussah, sind zeitgenössischen Zeitungsberichten zu entnehmen (vgl. anonym 1893). Die Einteilung in 19 Räume blieb bestehen, sie wurden lediglich dem neuen Zweck angepaßt. Sechs waren als Arbeitszimmer geplant. Eines für den Direktor, zwei weitere waren für die beiden Assistenten Hartlaub und Ehrenbaum bestimmt. Das vierte Zimmer wurde als Botanikerzimmer für Kuckuck eingerichtet, der Untersuchungen über die Meeresflora Helgolands anstellen wollte. Die beiden anderen Arbeitszimmer sollten Gästen der Station zur Verfügung stehen. Sie enthielten je zwei Arbeitsplätze für sogenannte „ambulante“ Gelehrte. Für den Fall, daß diese vier Gastarbeitsplätze nicht genügten, wollte man auch private Arbeitsplätze außerhalb des Instituts einrichten. Im Kellergeschoß wurde für Gastforscher ein Raum mit kleinen Aquarien geschaffen, in denen ein beständiger Wasserwechsel gute Bedingungen für das Untersuchungsmaterial gewährleistete. Auch eine größere Anzahl von Durchlüftungsapparaten neuester Konstruktion war vorhanden, sie ließen jedoch zunächst zu wünschen übrig und wurden später verbessert. Für die Aufnahme und das Sortieren des frischgefangenen Materials stand ein Sortierraum zur Verfügung. Außerdem gab es ein Zimmer für den Präparator, einen Chemikalienraum, ein Sammlungszimmer für das konservierte Material, ein Bibliothekszimmer und eine Kammer für Glassachen. Besonderes Augenmerk legte Heincke von Anfang an auf die Einrichtung der Bibliothek. Dank seiner Initiative erhielt die Station Schenkungen vieler Verleger. Heincke teilte ihnen seine und die Wünsche seiner Kollegen mit. So bemühte er sich nach dem Vorbild der Zoologischen Station Neapel, auch Zeitschriften kostenlos zu erhalten, darunter die „Zeitschrift für wissenschaftliche Zoologie“, das „Archiv für mikroskopische Anatomie“ und die „Jenaische Zeitschrift für Naturwissenschaften“. Die Bibliothek umfaßte, wie aus dem Jahresbericht des Direktors ( 8 ) hervorgeht, bereits 1892 eintausend Exemplare.

Auch das Kultusministerium trug zur Gestaltung der Anstaltsräume bei. Der Minister gab bei dem Landschafts- und Marinemaler Richard Eschke ${ }^{128}$ ein Ölgemälde in Auftrag, das die „Einfahrt in den Hafen von Bermuda“ darstellte und an die, wie es hieß, unter Führung des Geheimen Medizinalrats Professor Dr. Hensen (Kiel) im Jahre 1889 unternommenen „Plankton-Expedition“ erinnern sollte. Richard Eschke, Sohn des berühmten Künstlers Hermann Eschke ${ }^{129}$, der in England große Erfolge als Marinemaler feierte, hatte als sogenannter „Exkursionsmaler“ die Deutsche Atlantische Expedition begleitet. Das Werk des Künstlers wurde der Anstalt als Geschenk überreicht und im Treppenhaus aufgehängt:

128 Richard Eschke (1859-1944)

129 Hermann Eschke (1823-1900) 


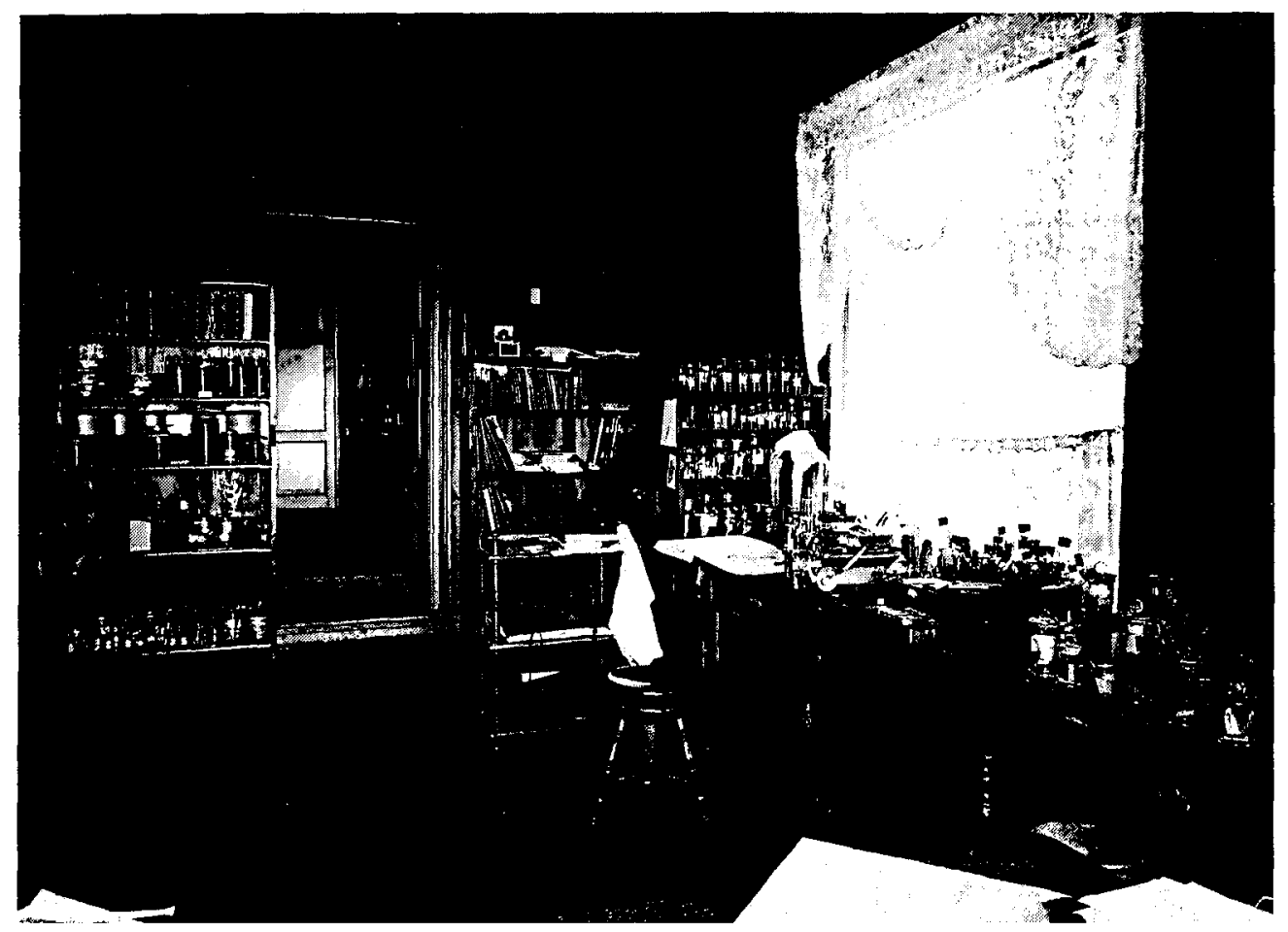

Abb. 22. Zum Labor umgewandeltes Zimmer im 1. Dienstgebäude der Königlichen Biologischen Anstalt Helgoland. Archiv der Biologischen Anstalt Helgoland.

Einige Zimmer des Anstaltsgebäudes wurden zeitweilig als Wohnungen genutzt. Da die Räume im Keller, die dem Fischmeister zugewiesen worden waren, aus gesundheitlichen Gründen als Wohnraum nicht zumutbar waren, stellte Heincke der Familie Diensträume bereit. Für das Schauaquarium war zunächst kein Platz.

Obwohl auch um die Jahrhundertwende die Räume der Anstalt ausreichten, rechnete der Direktor von Anfang an fest mit der Erweiterung der Station. Diese Vergrößerung werde sich, davon war Heincke überzeugt, zum einen aus den wachsenden Forschungsaufgaben ergeben, zum anderen aus der steigenden Anziehungskraft der Station für Kursteilnehmer und Besucher. In einem Artikel nannte Heincke seinen Grundsatz:

„daß die Anstalten, die wir haben, namentlich die Biologische Anstalt Helgoland, auch mit reichlicheren Mitteln ausgestattet werden mögen. Das Meer ist groß und man kann ihm mit kleinen Mitteln nicht beikommen“ (Heincke 1898).

Ganz in diesem Sinne bemühte sich Friedrich Heincke ständig um eine Erweiterung des Stationsgebäudes. Hierbei war er bestrebt, von bereits bestehenden Einrichtungen zu lernen. Schon 1892, also kurz nach Eröffnung der Biologischen Anstalt, beantragte er bei der Königlichen-Preußischen Akademie der Wissenschaften ein Reisestipendium, um im Frühjahr 1893 nach Neapel, Triest, Rovigno und Villafranca zu fahren:

„damit er (F. Heincke, d. V.) als Direktor der neugegründeten Biologischen Anstalt auf Helgoland und im Interesse der weiteren Entwicklung derselben in die Lage versetzt wird, eine größere Zahl zoologischer Meeresstationen des Auslandes näher kennenzulernen“" (145). 
Heincke begründete sein Anliegen damit, daß sich dieses Institut „nach Bedarf und Mitteln ... vergrößern (kann) und bei dieser, wie ich hoffe, baldigen und stetig fortschreitenden Entwicklung der örtlichen Verhältnisse und den besonderen wissenschaftlichen Zielen der Anstalt besser gerecht werden, als es bei der sofortigen Entwicklung eines größeren Instituts möglich gewesen wäre“ (145).

Der Antrag wurde genehmigt. Besonders wertvoll war, daß Friedrich Althoff den Antrag unterstützt hatte, der als Gegner kurzatmiger Entscheidungen galt und eine sehr langfristig konzipierte Wissenschaftspolitik vertrat. Ein Beispiel dafür ist seine Aufforderung an vierzehn Berliner Universitätsinstitute, ihren Raumbedarf und die Erweiterungsmöglichkeiten für die nächsten zwanzig Jahre anzumelden. In ihm hatte Heincke einen langjährigen Verbündeten.

In den nächsten Jahrzehnten mußte Heincke bei der Verwirklichung seiner Vorhaben mit zahlreichen Komplikationen fertigwerden. Ein Hindernis bei der Verwirklichung seiner Pläne war die Festlegung der Gemeinde aus dem Jahre 1893, daß kein Grund und Boden verkauft werden dürfe. Heincke konnte jedoch vereinbaren, daß nach Vollendung des neu zu erbauenden Posthauses das direkt neben der Anstalt gelegenen Gebäude der alten Post in den Besitz der Anstalt überging. Dieser Antrag wurde 1896 vom Abgeordnetenhaus bestätigt. Das alte Posthaus sollte für Kurse mit jüngeren Botanikern genutzt werden.

Da die Anstalt über mehrere Jahre keine eigene Seewasserleitung hatte, konnte das geplante Schauaquarium, das auch Besuchern zugänglich gemacht werden sollte, zunächst nicht eingerichtet werden. Man behielt das Vorhaben jedoch als dringenden Wunsch im Auge. Erst kurz nach Einweihung des Nordseemuseums im Jahre 1898 konnte Heincke den Bau eines Schauaquariums beantragen. Es wurde schon 1902 in einem schönen, massiven Backsteinbau eröffnet, der, folgt man zeitgenössischen Beschreibungen, einen starken Kontrast zu den sonstigen Bauten der Insel bildete. Eine Giebelwand, die dem Meer zugewandt war, sollte durch ein Mosaikbild verziert werden. Wegen dieses Kunstwerkes kam es im März 1902 zwischen dem Kultusministerium und dem Geheimen Zivilkabinett des Deutschen Kaisers und Preußischen Königs zu einem ausführlichen Schriftwechsel. Der Kaiser wurde in seiner Funktion als Preußischer König ausführlich über das Vorhaben unterrichtet und um Genehmigung gebeten (101). Hintergrund war, daß das Aquarium an hervorragender Stelle die Insel schmücken sollte und man sich von dem Mosaik auch für die vorbeifahrenden bzw. heimkehrenden Fischer und Seeleute vaterländische Inspiration versprach. Die dekorative Behandlung des Gegenstandes, so wurde ausdrücklich betont, sei älteren Motiven der mittelalterlichen Baumeister nachgebildet und namentlich auf Fernwirkung ausgerichtet. Ziel war es, die Wirkung des Baues und die naturwissenschaftliche und nationale Bestimmung des Gebäudes auch nach außen hin zu kennzeichnen. Der Entwurf stammte von dem Maler und Innenarchitekten August Oetken ${ }^{130}$. Oetken wurde durch Fresken und Mosaiken bekannt, so schuf er ein Mosaik in der Elisabeth-Kemenate der Wartburg zu Eisenach. Von 1907-1926 wirkte er als Lehrer für Ornamentik und farbiges Dekor an der Technischen Universität in Berlin-Charlottenburg. Das Mosaik am Aquarium der Anstalt sollte aus Glas gefertigt sein und eine Breite von $31 / 2 \mathrm{~m}$ haben. Es stellte einen gekrönten Adler dar, der über den Wassern schwebt. In dem Streifen unter dem Halbrund sollten die auf die Meeresbiologie hinweisenden Worte des Thales aus dem II. Teil von Goethes „Faust“ Platz finden:

130 August Oetken (geb. 1868) 
„Alles ist aus dem Wasser entsprungen,

Alles wird durch das Wasser erhalten;

Ozean, gönn uns dein ewiges Walten!“

Die Genehmigung zur Anbringung des Mosaiks, das zusätzliche Kosten verursachte, wurde im März 1902 erteilt (102).

Das Gebäude der Anstalt, das aus mehreren alten Einzelhäusern bestand, erwies sich - wie es Heincke vorausgesehen hatte - bald als Provisorium. Bereits wenige Jahre nach Eröffnung der Anstalt signalisierte Heincke dem Kultusministerium, durch die Vergrößerung des Mitarbeiterstabes seien die Raumverhältnisse so beengt, daß die Arbeitsfreude der Mitarbeiter langsam gehemmt werde ... Diese Mitteilung wurde zwar vom Kultusministerium an das Finanzministerium weitergegeben, wurde von dort aber sofort zurückgewiesen. Immerhin erreichte Heincke, daß 1903 ein „Erläuterungsbericht und Kostenüberschlag zum Vorentwurf für den Neubau der Königlichen Biologischen Anstalt zu Helgoland" erstellt wurde. Dieser Entwurf schloß mit $432000 \mathrm{M}$ ab. Er sah vor, das derzeitige Gebäude der Anstalt abzureißen. Außerdem schlug Heincke vor, die Logierhäuser „Villa Franz" und "Kaiser von Deutschland" anzukaufen. Auch diese beiden Gebäude wollte Heincke abreißen lassen und auf dem Baugrund aller drei Häuser ein neues Gebäude bauen lassen. Der Plan verschwand für über drei Jahre in der Schublade. Erst 1906 wurde die Idee wieder erörtert. Das Finanzministerium stand Heinckes Vorstellungen, trotz der Neubaupläne alte Gebäude anzuschaffen, sehr kritisch gegenüber. Als sich nun noch herausstellte, daß Heincke die Gebäude nur erwerben wollte, um sie abreißen zu lassen, lehnte man zunächst ab. Heincke begründete nun sehr diplomatisch, daß es sich um sehr günstige, einmalige Gelegenheiten handele und auf diese Weise der Fiskus billig zu Grund und Boden komme. Unter dieser Bedingung stimmte der Finanzminister zu. Heinckes Annahme, daß er die Gebäude preiswert erwerben könne, sollte sich jedoch als Irrtum erweisen. Die Verhandlungen mit dem sehr geschäftstüchtigen Peter Franz zogen sich über Jahre hin und erwiesen sich als sehr schwierig.

Was den Institutsneubau anging, so hatte Heincke ehrgeizige Pläne. Er wollte auf der verfügbaren Grundfläche von 550 Quadratmetern einen, wie er sich ausdrückte, ordentlichen, allen modernen Anforderungen an ein wissenschaftliches Institut und an den erweiterten Betrieb der Anstalt genügenden Neubau errichten. Er sollte sich unmittelbar an ein neues Aquarium anschließen (9). Heincke stützte seine Vorschläge auf internationale Vergleiche mit anderen Stationen, darunter die in Neapel, Plymouth und in Bergen, die er auf seinen Studienreisen kennengelernt hatte. Danach sollte das neue Gebäude folgendermaßen aussehen: Kellergeschoß, Erdgeschoß, zwei Hochetagen und Dachgeschoß. Der Keller sollte aus drei Räumen bestehen, in denen sich wissenschaftliche Versuchsaquarien, der Maschinenraum für die Aquarien, ein Raum für die Heizung und die Toiletten befinden sollten. Das Erdgeschoß sollte acht Arbeitszimmer für wissenschaftliche Beamte enthalten, zwei Laboratorien mit je fünf bis sechs Arbeitsplätzen, drei einzelne Arbeitszimmer für ambulante Gelehrte. Im ersten Geschoß war ein Hörsaal für Vorträge und wissenschaftliche Kurse vorgesehen, ein Bibliotheksraum, ein Arbeitszimmer für den Direktor und sein Büro, zwei Räume zum Sortieren des Fangmaterials, ein Präparatorzimmer, ein Zimmer für Hauswart und Diener, ein Zimmer für die zoologische Abteilung, zwei Sammlungszimmer für die botanische Abteilung, sechs Zimmer für Instrumente, chemisch-hydrographische Arbeiten, ein physiologisches Labor und ein Raum für Photoarbeiten. Das zweite Geschoß sollte die zweihundert Quadratmeter große Dienstwohnung des Direktors beherbergen und die fünfzig Quadratmeter große des Hauswarts. Außerdem war an eine Dienstwohnung für einen verheirateten Assistenten gedacht. Im Dachgeschoß sollte ein großer Raum sein, in dem Netze und wissenschaftliche Fanggeräte aufgehängt werden konnten. 
Auch ein Trockenboden war eingeplant. Desgleichen sollten Hochbassins für Seewasser und Süßwasser, Räume zur Aufbewahrung von Glassachen und weitere Dienstwohnungen untergebracht werden.

Der Entwurf wurde mehrfach diskutiert und immer wieder ergänzt.

In bewährter Weise beriet sich das Kultusministerium mit bekannten Wissenschaftlern und holte Meinungen zum Projekt ein. So wurde der Rektor der Landwirtschaftlichen Hochschule zu Berlin, der Physiologe Nathan Zuntz ${ }^{132}$, als Gutachter herangezogen (10). Auch Franz Eilhard Schulze, der sich schon um die Stationsgründung verdient gemacht hatte, wurde wieder befragt. Er war inzwischen zum Direktor des Zoologischen Instituts der Friedrich-Wilhelms-Universität zu Berlin berufen worden. Auch andere Kapazitäten wurden gebeten, ihre Meinung zu äußern, so der Entomologe Friedrich Moritz Brauer ${ }^{132}$ und Albrecht Penck ${ }^{133}$, Direktor des Instituts für Meereskunde in Berlin. Alle Gutachter äußerten sich übereinstimmend lobend über Heinckes Projekt, insbesondere Zuntz hob die Sachkenntnis und große Umsicht hervor, mit der Heincke vorgegangen war. Penck benutzte allerdings die Gelegenheit, um auf die mangelhaften Arbeitsbedingungen seines 1901 in Berlin gegründeten Instituts und des Museums für Meereskunde an der Universität hinzuweisen, und machte einen Anspruch auf acht Räume in der zu erbauenden Helgoländer Anstalt, darunter eines Hörsaals geltend. Er begründete dies mit der Notwendigkeit,

„seine (des Instituts für Meereskunde d. V.) in der Reichshauptstadt naturgemäß nur theoretische Arbeit unmittelbar am Meere auch nach der praktischen Seite hin zu ergänzen" (11).

Albrecht Penck hatte im Januar 1906 die Leitung des Instituts für Meereskunde übernommen, das er zusammen mit dem Geographischen Institut bis 1921 leitete. Dem Institut, das er mit großer Unterstützung des Kaisers und des Kultusministeriums ins Leben gerufen hatte, ging es besonders um eine intensive Zusammenarbeit mit der Kriegsmarine. So leitete das Reichsmarineamt eine freiwillige Zusammenarbeit der Schiffskommandos und der einzelnen Offiziere an den Aufgaben des Instituts ein, u. a. wurde die Sammeltätigkeit für die ozeanographischen Abteilungen, Vervollkommnung der Reichsmarinesammlung und die Gründung eines Archivs für die Geschichte der Kriegsschiffe bei der Reichsmarineverwaltung erwogen. Trotz der Bedeutung, die Institut und Museum staatlicherseits beigemessen wurde, konnte die Raumnot der Institution mindestens bis 1921 nicht beseitigt werden (vgl. Lies und Pech 1986).

Zwischen der Anstalt und dem Institut für Meereskunde Berlin blieb - wie auch aus anderen Akten hervorgeht - eine unterschwellige Konkurrenz bestehen, da Heincke es offenbar verstand, Bedürfnisse und Interessen seines Instituts erfolgreicher zu vertreten als Penck. Trotz prinzipieller Zustimmung von Kultus- und Finanzministerium zu Heinckes Projekt wurde die Realisierung durch neue Schwierigkeiten erschwert. Das Projekt - man hatte sich 1906 auf etwa 245000 Mark geeinigt (13) - wurde immer teurer und erreichte inzwischen aufgrund der auf der Insel rapide steigenden Preise einen Wert von mehr als einer halben Million. Zudem zogen sich die Verhandlungen mit Peter Franz hin. Auch er verlangte immer mehr Geld. Es kam zu einem umfangreichen Schriftwechsel zwischen Kultusministerium und Finanzministerium. Der Finanzminister war nicht bereit, die erhöhten Kosten zu tragen, und das Projekt wurde genauestens daraufhin untersucht, wo man kürzen könnte. Vor allem beklagte er sich darüber, daß in dem Plan wiederum ein

131 Nathan Zuntz (1847-1920)

132 Friedrich M. Brauer (1832-1904)

133 Albrecht Penck (1858-1945) 
großes wissenschaftliches Versuchsaquarium vorgesehen sei. Der Finanzminister zog alte Anträge aus der Schublade und erinnerte daran, daß Heincke 1899 den Bau eines Schauaquariums damit begründet habe, daß dies nun eine Dauerlösung sei. Der Finanzminister bemerkte verärgert:

„Nach allem kann ich in der Bauskizze nur eine technische Darstellung und Schätzung der finanziellen Tragweite der Forderungen des Direktors erblicken, dem in dem Maße seiner Ansprüche der harte Ernst der finanziellen Lage offenbar noch nicht erkennbar geworden ist, der im übrigen aber auch bei der Geltendmachung seiner Wünsche vielfach von unzutreffenden Voraussetzungen ausgeht" (16).

Die Diskussionen wurden durch die Kriegsvorbereitungen unterbrochen.

Bereits 1906 begannen auf Helgoland die Vorbereitungen für den Festungsbau. So wurden ab 1906 Sprengungen für die Anlage eines Torpedohafens durchgeführt und bombensichere unterirdische Offiziersräume gebaut. Es wurden Beobachtungen darüber durchgeführt, welche Wirkung die Erschütterung der Insel durch Geschützfeuer haben könnte. So wurden im Dezember 1907 Versuche mit 28-cm-Haubitzen durchgeführt. Am 11. 2. 1908 teilte der Staatssekretär im Reichsmarineamt dem Innenministerium mit, daß die Anwendung der kaiserlichen Verordnung betreffend Reichskriegshäfen auf Helgoland geprüft werden solle, wonach z. B. alle baulichen Anlagen überwacht würden:

„Ihr Erlaß (einer solchen Verordnung, d. V.) erscheint mir jetzt geboten. Die Gründe dafür sind in dem steigenden militärischen Werte Helgolands in einem Seekriege, in den Deutschland verwickelt wird, zu suchen" (137).

In diesem Jahr wurde Helgoland zur deutschen Festung ausgebaut (89). Man begann mit dem Bau eines neuen Kriegshafens. Außerdem wurden Festungs- und Garnisonsbauten in Angriff genommen. Damit setzte ein lebhafter Baubetrieb auf der Insel ein, und die schweren Fahrzeuge störten die Ruhe beträchtlich. Italiener und andere Fremdarbeiter kamen, um beim Hafenbau zu helfen. Auf der Helgoländer Reede lagen nun Minenleger, Scheibenfahrzeuge und Peilboote der Marine, es herrschte Gedränge auf der Reede und es wurde immer schwieriger und gefährlicher für einlaufende Schiffe, einen geeigneten Ankerplatz zu erreichen. Dadurch wurde der Badebetrieb erheblich beeinträchtigt, zumal es sogar passierte, daß schwere Zementblöcke auf das Wasserrohrsystem des Warmbadehauses rollten und es so beschädigten, daß das Haus geschlossen werden mußte.

Es läßt sich denken, daß es zu Spannungen mit der Gemeindeverwaltung kam, da die Helgoländer vom Badebetrieb lebten. Auch die Reeder der Hamburg-Amerika-Linie und der Norddeutsche Lloyd, die Badegäste brachten, sahen ihr Geschäft beeinträchtigt. Sie beschwerten sich beim Ministerium für Handel und Gewerbe. Daraufhin kam es zu einem umfangreichen Schriftwechsel zwischen diesem Ministerium und dem Reichsmarineamt. Sowohl die Gemeindeverwaltung als auch die Schiffseigner befürchteten, daß die Schönheit der Insel durch den Festungsbau beeinträchtigt werde und damit an Anziehungskraft für Touristen verliere. Zweitens sei abzusehen, daß infolge des Hafenbaus, dessen Anlagen mehr als tausend Meter ins Meer hinausreichen sollten, die Rundfahrten um Helgoland aufhören und damit die Bevölkerung eine wichtige Einnahmequelle verlieren würde.

Die Helgoländer Gemeinde ging schließlich, als alle Proteste nichts fruchteten, so weit, die Reichsmarineverwaltung auf Unterbrechung des Hafenbaus zu verklagen. Grundlage ihrer Klage war die Berufung auf „alte Rechte“ der Helgoländer Bevölkerung. Diese „alten Rechte" bestanden in der Zusicherung, daß sie das alleinige Nutzungsrecht des Strandes und die Hoheitsrechte auf Meer und Klippen bis zu einer Grenze von 3 Seemeilen habe. Es fiel jedoch den Helgoländern schwer, diese Rechte zu belegen. So seien sie zwar überliefert, aber nicht in Urkunden festgeschrieben. Die Bürger beriefen sich auf die Autorität des Polizei- und Gerichtssekretärs a. D. Botter und betonten, daß er zwar körperlich leidend, aber 
geistig völlig normal sei. Sie befürchteten jedoch, daß das Alter und der schlechte Gesundheitszustand des Zeugen die Besorgnis rechtfertige, daß dieser Zeuge als „Beweismittel“ verlorengehen könnte. Der Regierungspräsident von Schleswig ging auf die Vorwürfe nicht ein, er charakterisierte die Einwände der Helgoländer als unhaltbar und bestritt, daß die Rechte weiterhin gälten. So könne es ja beispielsweise nicht angehen, daß das noch im 19. Jahrhundert zwischen Helgoländern, Blankenesern und Finkenwerdern praktizierte Faustrecht, das gewalttätige Wegnehmen von Netzen und die Kapereien, sanktioniert werde. Bei den Auseinandersetzungen mit diesen von den Einheimischen als „Coxsenklappers“ bezeichneten Räubern habe man Signale, Flaggen und manchmal sogar Schußwaffen benutzt. Das Recht des „Ausbootens“ aber, durch den Sansibar-Vertrag festgelegt, werde man weiterhin sichern. Selbstverständlich fuhr man im Hafenbau fort, denn die Belange der „Landesverteidigung" hatten Priorität gegenüber den Wünschen der Bevölkerung. Auch alle weiteren Beschwerden der Helgoländer wurden abgewiesen.

Was die Anstalt anging, so wuchs bei der Regierung die Unsicherheit darüber, ob es richtig sei, angesichts des Ausbaus zur Festung überhaupt noch auf Helgoland einen Neubau zu errichten. Hinzu kam die schon erwähnte plötzlich einsetzende Teuerungswelle auf der Insel. Vermutlich stiegen die Grundstückspreise auch deshalb, weil durch Ankäufe seitens der Marine ein Mangel an Grund und Boden einsetzte.

Es wurde vom Finanzministerium ernsthaft erwogen, das Neubauprojekt auf Helgoland zu streichen und die Anstalt auf das Festland zu verlegen. In dieser Sache kam es zu einem heftigen Schlagabtausch zwischen Kultus- und Finanzministerium. Das Kultusministerium warf dem Finanzministerium vor, daß für die Marine schließlich Geld da sei, nur für die Wissenschaft nicht, es seien aber finanzielle Opfer nötig im Dienste von Wissenschaft und Praxis. In diesem Zusammenhang wurde an alte Gutachten erinnert. Die Diskussionen zogen sich vom September 1910 bis November 1911 hin. Das Kultusministerium ließ noch einmal Gutachten von Spezialisten einholen zu der Frage, ob

„angesichts der auf der Insel herrschenden Teuerungsverhältnisse . . e eine Verlegung der Anstalt auf eine dem Festland näher liegenden Inseln oder an die Festlandküste selbst möglich sei“ (146).

Das Kultusministerium nahm seine Aufgabe wahr, an wissenschaftliche Interessen zu erinnern. Es wurde ausdrücklich betont, daß nicht die finanzielle Seite allein entscheidend sein könne, vielmehr ginge es darum herauszufinden, ob Helgoland aus wissenschaftlicher Sicht tatsächlich der günstigste Standort sei.

Wiederum wurden Gutachten eingeholt, so von der Königlich-Preußischen Akademie der Wissenschaften. In der Sitzung der physikalisch-mathematischen Klasse vom 19. 11. 1911 kamen die Akademiemitglieder nach Anhörung der Gutachter Franz Eilhard Schulze, Oscar Hertwig und Adolf Engler ${ }^{134}$, ab 1884 o. Professor für Botanik und Direktor des Botanischen Gartens in Berlin, zu dem Ergebnis, daß keine andere Stelle der deutschen Nordseeküste eine Fauna und Flora biete, die der Helgoländer an wissenschaftlichem Werte gleichkomme, so daß eine Verlegung der Einrichtung von Schaden wäre (147). Im selben Sinne äußerten sich die Mitglieder der Königlichen Gesellschaft der Wissenschaften zu Göttingen. Das Gutachten wurde u. a. von Heinrich Ehlers unterzeichnet (107). Trotz dieser günstigen Aussagen konnte das Projekt vorerst nicht in Angriff genommen werden.

Heincke war überzeugt davon, daß die Anstalt auf der Insel verbleiben würde. Er bemühte sich um weitere Verbesserungen am Anstaltsgebäude und beantragte 1913 einen kleinen Anbau, um einen Sortierraum einrichten zu können. Auch an die optische Gestaltung der Innenräume der Anstalt dachte er und erwarb die Fotoplatten der schönen Aqua-

134 Adolf Engler (1844-1930) 
riumsaufnahmen des Helgoländer Fotografen Franz Schensky ${ }^{135}$. Sie schmückten von nun an das Treppenhaus.

Während die Diskussionen um das Neubauprojekt liefen, kümmerte sich Heincke intensiv darum, Wohnungen für seine Mitarbeiter zu beschaffen. Mit großem Geschick besorgte er Grund und Boden auf dem Oberland. Auch das Grundstück der Witwe von Peter Eilers, Dorothea Eilers, welches an der Siemensterrasse lag, konnte angekauft werden. Der Bau der Kustodenwohnhäuser wurde für 1912 bewilligt. Nun trat aber der Fall ein, daß den beiden Kustoden Mielck und Kuckuck die Wohnungsverträge von den Vermietern schon 1911 gekündigt werden sollten. Hinzu kam, daß die Wohnung Paul Kuckucks zahlreiche Mängel aufwies und selbst für den äußerst bescheidenen Mann und seine Familie unzumutbar war. Kuckuck, der ja schriftstellerisches Talent besaß, schilderte mit viel Sinn für Dramatik, daß am 8. 11. 1910 durch den Südweststurm drei Fensterflügel abgerissen worden seien und Regenschauer das Wohnzimmer überschwemmt hätten. Das Wasser dringe zwischen Mauerwerk und Fensterrahmen ein und bilde auf den Dielen große Lachen. Zugleich blase der Wind so stark durch die zahlreichen Lücken, daß Gardinen und Vorhänge ständig flatterten. Im Winter 1909 habe die Familie 250 Eimer Schnee aus dem Hause schaffen müssen. Das Haus sei hundert Jahre alt und nur aus Helgoländer Erde ohne Mörtel erbaut. Deshalb seien die Wände so morsch, daß Ziegelsteine auf der einen Seite herausfielen, wenn man auf der anderen einen Nagel einschlage. Das Haus sei nur

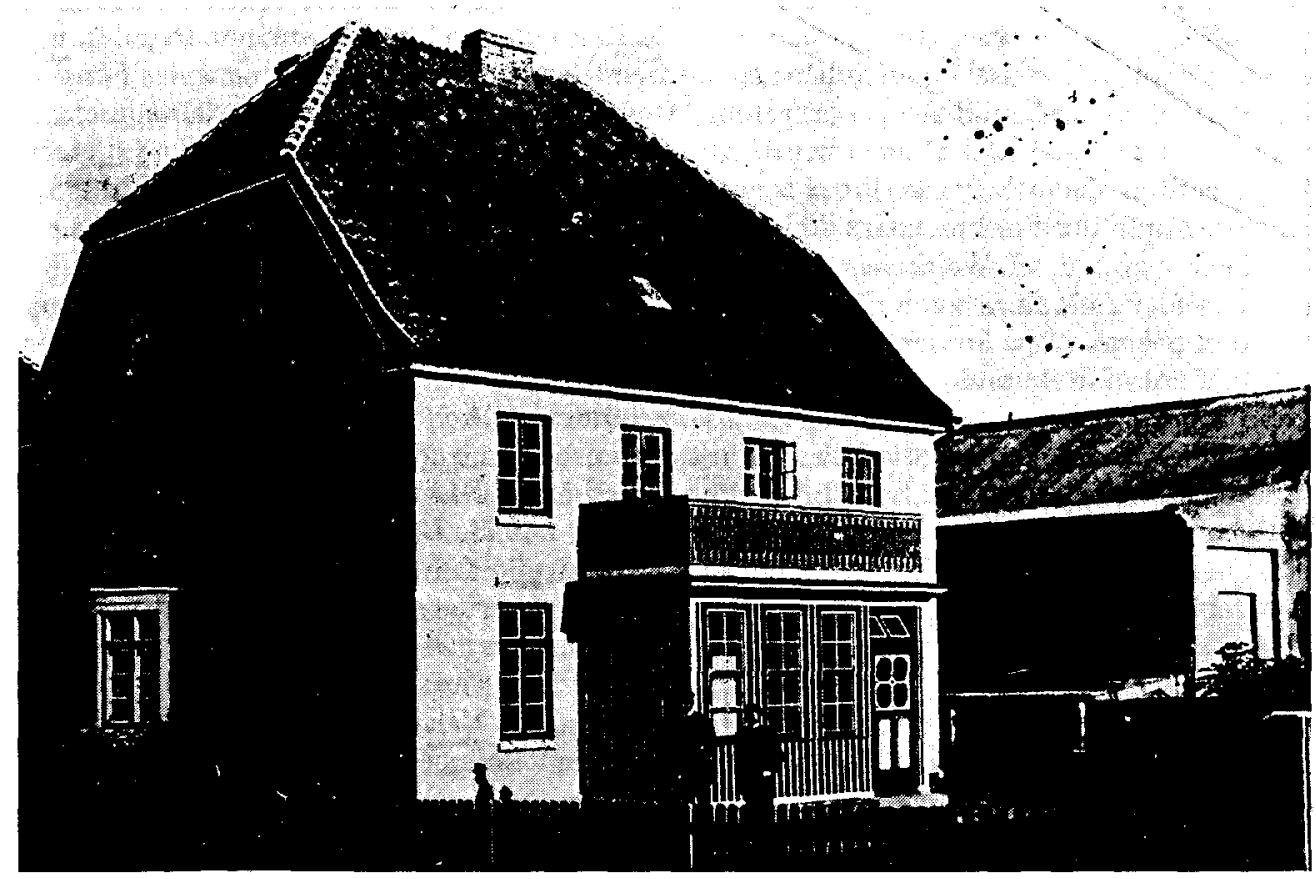

Abb. 23. Kustodenwohnhaus auf dem Oberland. Aufnahme um 1913. Archiv der Biologischen Anstalt Helgoland.

135 Franz Schensky (1871-1957) 
an einer winzigen Stelle unterkellert, in Dielen, Decken und an den Wänden wuchere der Schwamm. Infolge der schlechten Wohnbedingungen, die auch durch mehrere Gutachten bestätigt wurden, wären er und seine Frau krank geworden. Seine Frau, die große gesundheitliche Beschwerden habe, sei gezwungen, die kältesten Wochen über Weihnachten und Neujahr bei ihrer Mutter zu verbringen. Er dagegen müsse leider bleiben, da seine Arbeiten drängten.

Weil sich die Bauarbeiten an den neuen Kustodenwohnhäusern hinzogen, beurlaubte Heincke seinen Mitarbeiter Kuckuck ab 1912 von der Insel Helgoland. Kuckuck nahm die Gelegenheit wahr, an der Station in Rovinj zu arbeiten bzw. im Botanischen Garten der Friedrich-Wilhelms-Universität in Dahlem. Die beiden Kustodenwohnhäuser auf dem Oberland am Leuchtturmwege für Paul Kuckuck und Wilhelm Mielck wurden erst 1913 fertiggestellt. Die künftigen Bewohner nutzten die Möglichkeit, weitere Verbesserungen zu beantragen. So bat Paul Kuckuck um eine weitere Mädchenkammer, eine Abstell- und Kofferkammer auf dem Dachboden und die Vergrößerung der Zisternenanlage (81). Auch Clemens Hartlaub erhielt ein sogenanntes Kustodenwohnhaus auf dem Unterland in der Viktoriastraße gegenüber dem Anstaltsgebäude, dem Fischmeister wurde das renovierte Eilersche Haus an der Siemensterrasse zugesprochen.

Außer den drei Kustodenwohnhäusern und dem Haus für den Fischmeister wurde das Logierhaus „Prince of Wales“ erworben und für den Direktor als Dienstwohnung hergerichtet. In einem Teil des Gebäudes konnte die wertvolle Institutssammlung untergebracht werden. Skurrilerweise, das soll nebenbei erwähnt werden, kam es zwischen Heincke und den benachbarten Besitzerinnen der Pension Moltke, den Geschwistern Brodersen, zu langjährigen kleinlichen Streitereien. Die Häuser standen so eng aneinander, daß ein schmaler Gang dazwischen nicht benutzt werden konnte, wenn die Brodersens das Fenster öffneten. Heincke bemühte sich jahrelang, das Öffnen der Fenster per Gerichtsbeschlu $\beta$ verbieten zu lassen. Der Prozeß wurde durch den I. Weltkrieg unterbrochen und danach weitergeführt. Heincke verlor ihn. Insgesamt waren für die Wohnhäuser des Direktors, der Kustoden und des Fischmeisters $296000 \mathrm{M}$ ausgegeben worden.

Der Beginn des I. Weltkrieges beeinträchtigte die wissenschaftlichen Arbeiten. Einige Gebäude der Anstalt mußten völlig umgebaut werden. Das Aquarium wurde wegen seiner vorgeschobenen Lage an der Ostecke des Unterlandes zu einem mit Maschinengewehren und anderen Nahkampfmitteln bewaffeneten Blockhaus ausgerüstet. Ziel war es, einen Landungsversuch eventueller Gegner $\mathrm{zu}$ verhindern. Auch die gerade fertiggestellten Kustodenwohnhäuser von Mielck und Kuckuck wurden verändert. Das Dach und das oberste Stockwerk mußten zur Schaffung eines freien Schußfeldes für die schwere Artillerie entfernt werden. Wissenschaftliche Einrichtungen, wie die kleine Erdbebenstation, wurden außer Betrieb genommen und gingen in den Besitz der Marine über. Der mit viel Mühe angelegte botanische Garten, der ab 1910 auch als Vogelfanggarten diente, konnte anfänglich noch genutzt werden, wurde aber nach Evakuierung der Bevölkerung durch Nutzviehhaltung völlig zerstört. Heincke charakterisierte die Situation rückblickend so:

„In dem militärisch beschlagnahmten, teilweise für Verteidigungszwecke umgewandelten, von Drahtzaun umgebenen Gebäude, kommt kein Gelehrter mehr zur wissenschaftlichen Arbeit“ (25).

Nur noch wenige Wissenschaftler und Angestellte arbeiteten auf Helgoland. Sofort bei Kriegsausbruch wurden dienstverpflichtete Beamte einberufen. Nach kurzer Zeit wurden schließlich alle gezwungen, mit der gesamten Zivilbevölkerung auf das Festland überzusiedeln. Die Geschäftsstelle wurde nach Oldenburg verlagert, die Sammlungen ebenfalls nach Oldenburg verbracht. Zum Glück blieb die Anstalt, wie der Direktor 1918 berichten konnte, von schwereren Angriffen verschont. 
Die Geschäftsstelle konnte ab 15. 7. 1919 wieder nach Helgoland umziehen. Dennoch waren neue Probleme in Sicht: Pressekampagnen um die deutschen Friedensverhandlungen nährten die Befürchtung, daß Helgoland nicht deutsch bleiben würde, sondern an England zurückgegeben werden müßte, was das sichere Ende der Königlichen Biologischen Anstalt auf Helgoland bedeutet hätte. Es läßt sich denken, daß diese Ungewißheit die wissenschaftliche Arbeit behinderte. Heincke erkundigte sich mit Schreiben vom 31. 3. 1919 im Kultusministerium:

„Ich bitte gehorsamst um eine geneigte Mitteilung, ob der preußischen Regierung schon etwas Bestimmtes über das endgültige Schicksal Helgolands bekannt ist, und in jedem Falle um Verhaltungssvorschriften“ (23).

Helgoland blieb deutsch, und die Zukunft der Anstalt, die in Preußische Biologische Anstalt Helgoland umbenannt wurde, schien für einige Zeit gesichert. Dennoch bedeutete die Nachkriegszeit einen Neuanfang. Es galt, die nach fast vierjähriger Unterbrechung niederliegende oder auf ein Minimum reduzierte Arbeit unter erschwerten Bedingungen wiederaufzunehmen (29). Heincke verlor drei seiner besten Mitarbeiter, hinzu kamen die schlechte finanzielle Lage und die internationale Isolierung Deutschlands. Etwa ab 1921 verringerten sich die Finanzen der Anstalt so dramatisch, daß sich Fachkollegen aus ganz Deutschland dafür einsetzten, die Institution aus ihrer Notlage zu befreien. Wissenschaftlern wie Willy Kükenthal ${ }^{136}$, ordentlicher Professor für Zoologie und Leiter des Museums für Naturkunde, Eugen Korschelt, ordentlicher Professor in Marburg und Herausgeber des zehnbändigen „Handwörterbuches der Naturwissenschaften“, sowie Alfred Kühn ${ }^{137}$, seit 1920 ordentlicher Professor in Göttingen, erarbeiteten eine Denkschrift zur Weiterführung der Biologischen Anstalt auf Helgoland (31). Die Kollegen engagierten sich auch für den Erwerb eines neuen Schiffes, für die Einrichtung mehrerer Planstellen, darunter einer Kustodenstelle für einen Ornithologen, sowie den Erwerb des Trossenschuppens zur Durchführung von Kursen.

Immerhin bewog diese Solidaritätskundgebung den Kultusminister dazu, die Forderungen trotz angespanntester Finanzlage in den Staatshaushaltsplan für 1922 aufzunehmen.

Die Marine hatte zahlreiche Gebäude zurückgelassen. Heincke und Mielck erkannten rechtzeitig, daß dies eine Chance war, die Gebäude für friedliche Zwecke im Dienste der Anstalt zu nutzen (24). Friedrich Heincke wandte sich an den Vorsitzenden der MarineKontrollkommission in Berlin, Admiral Charleton, und an den Vorsitzenden der interalliierten Subkommission in Helgoland, Kapitän Willan, mit der Bitte um Hilfe. Sie verstanden es, am Beispiel des Marinehafens klarzumachen, daß die Biologische Anstalt einen zu allen Jahreszeiten geschützten Hafen brauche und

„daß England verpflichtet sei, die Anstalt im Interesse der Wissenschaft und der internationalen Meeresforschung lebensfähig zu erhalten" (97).

Daraufhin, so Heincke weiter, sei die Entente-Kommission der Anstalt nennenswert entgegengekommen, indem sie folgende Zugeständnisse gemacht habe: Sie hat erlaubt, daß die Anstalt an die Außenseite der Nordostmole einen kleineren Hafen für die „Augusta“ aus den Abbruchstücken des Marinehafens anbauen konnte, dessen Lage und Größe allerdings der Genehmigung der Entente-Kommission bedürfe. Ferner gestand die Entente zu, daß der frühere Trossenschuppen, der als einziges von allen Hafengebäuden erhalten geblieben war, der Anstalt für wissenschaftliche Zwecke überlassen werde. Daran war jedoch die Bedingung gebunden, daß die Biologische Anstalt sich bereit erklärt, die Kosten für den

136 Willy Kükenthal (1861-1922)

137 Alfred Kühn (1885-1968) 


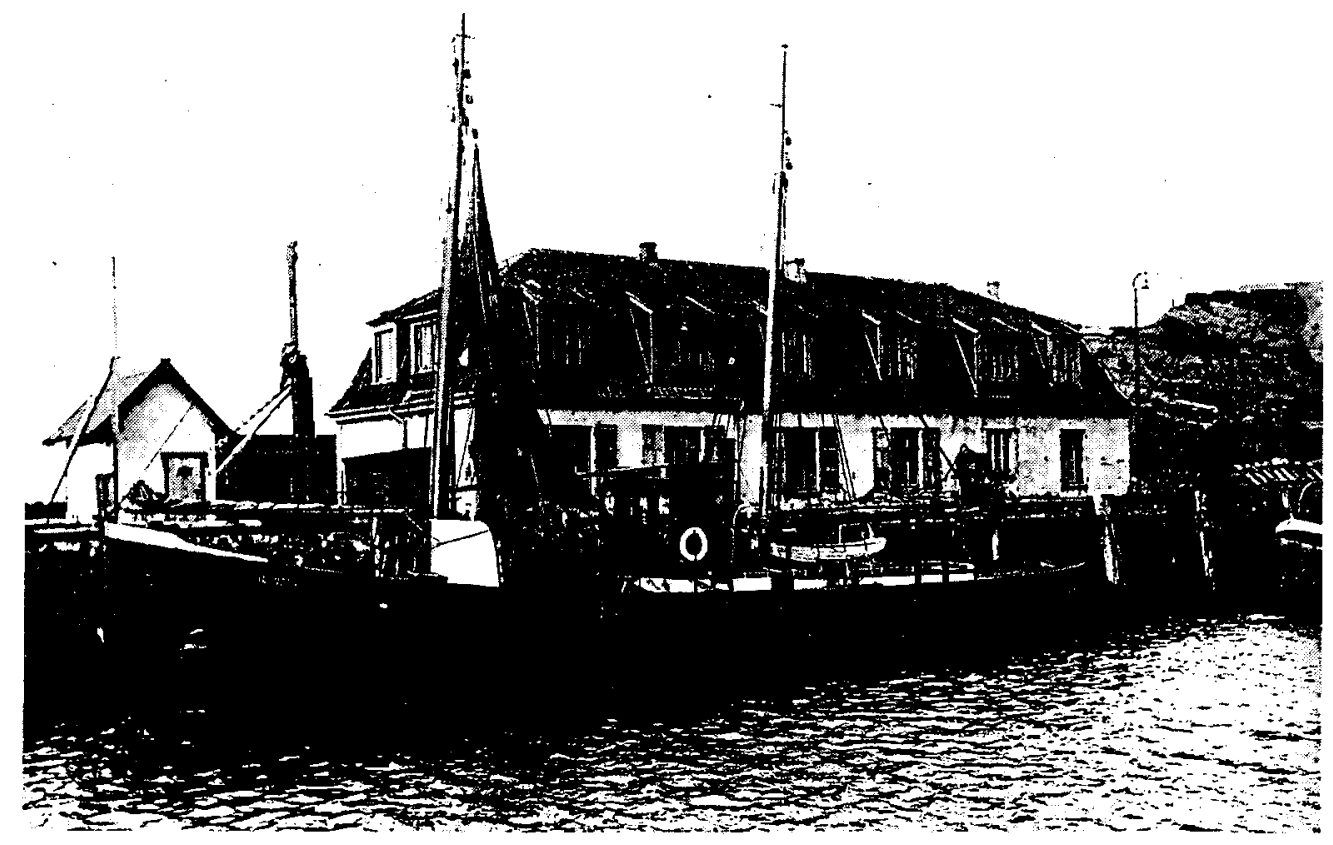

Abb. 24. Trossenschuppen, später Hafenlabor im Augustahafen. Foto: Dr. Klocke, Archiv der Biologischen Anstalt Helgoland.

Bau des ,Augusta"-Hafens und für die Einrichtung und Unterhaltung des Trossenschuppens zu tragen. Der von der Anstalt vorgelegte Plan wurde am 1. November 1920 vom alliierten Unterausschuß uneingeschränkt genehmigt. Heincke drückte seine Freude darüber aus, daß viel erreicht sei,

,jedenfalls alles, was überhaupt von der Entente erreichbar ist und erheblich mehr, als der Wortlaut des Friedensvertrages erwarten ließ“ (97).

Nun ergab sich eine neue Schwierigkeit - die Forderungen der Anstalt mußten innerstaatlich genehmigt werden. Das erwies sich wegen der bedrängten Lage der Staatsfinanzen als sehr kompliziert, da das Reichsschatzministerium ein Interesse daran hatte, Immobilien meistbietend zu verkaufen. Heincke und Mielck versuchten, ihre Forderungen durch Mitgliedschaft im deutschen Unterausschuß, der gebildet worden war, um die sogenannte „Entfestigung“ von Helgoland zu beschließen und zu kontrollieren, durchzusetzen. In diesen Ausschuß waren sie im Auftrage des Preußischen Ministeriums für Wissenschaft, Kunst und Volksbildung und des Reichsernährungsministeriums gelangt. Beide Institutionen hatten ein gewisses Interesse daran, daß die Anstalt in den Besitz der Gebäude gelangte. Der Unterausschuß sollte allerdings schon 1921 auf Betreiben des Reichsschatzministeriums aufgelöst werden. Nach Meinung von Heincke und Mielck hatte er jedoch die für die Anstalt und die Seefischerei wichtigsten Aufgaben, nämlich die Marinegebäude an die Anstalt zu übergeben, nicht erfüllt. Besonders erbitterte die Gelehrten, daß der Ausschuß die ,von der Entente z. T. ausdrücklich allein für die Biologische Anstalt gemachten Zugeständnisse aus fiskalischen Rücksichten der Anstalt nicht oder wenigstens nicht ungeschmälert zu Gute kommen lassen will“ (36). 
Heincke und Mielck warfen dem Reichsschatzministerium vor, die Marinegebäude als Immobilien meistbietend veräußern zu wollen, um für den Reichsfiskus maximale Einkünfte zu erzielen. Energisch wandten sie sich gegen Pläne, die Anlagen und Gebäude einer Privatgesellschaft zur Einrichtung eines modernen Seebades zu übergeben. Was die Hafenanlagen anging, so sollten sie in Erfüllung des Versailler Vertrages "geschleift" werden. Die Wissenschaftler gingen so weit zu behaupten, daß von den bevorstehenden Entscheidungen die Existenz und Zukunft ihrer Einrichtung abhinge und es bei der Frage nach der Verbesserung und Verwendung der verbliebenen Hafenanlagen um nicht weniger ginge als um das Leben und die Sicherheit der Fischer und ihrer wertvollen Fahrzeuge.

Ihre Argumentation ging dahin, daß es genug Seebäder gäbe, aber nur eine biologische Anstalt an deutschen Meeren und es deshalb gelte, die Insel der Wissenschaft zu erhalten und in den Dienst nationaler Arbeit zu stellen, sei sie nun wissenschaftlich oder praktisch im Interesse der Seefischerei, der allgemeinen Volkswohlfahrt oder der berechtigten Interessen der Helgoländer als eines deutschen Stammes (37).

Heincke und Mielck kamen die Solidaritätsbekundungen von Fachkollegen zu Hilfe, und sie konnten erreichen, daß ihnen einige Gebäude übergeben wurden. So konnte in dem Trossenschuppen das Hafenlaboratorium untergebracht werden, außerdem durfte er für die Durchführung von Kursen genutzt werden. Sogar ein aus Eisenbeton errichteter Unterstand für einen Scheinwerfer und das Dienstpersonal blieb erhalten. Mielck und Heincke erreichten, daß dorthin die kleine Erdbebenstation verlegt wurde, die jetzt von der Anstalt betreut wurde (90). Auch das ehemalige Stabsoffiziersgebäude der Marine auf dem Oberland wurde gewonnen, und 1926 wurde dort die Vogelwarte untergebracht (vgl. Vauk 1977). Für sich selbst bemühte sich Mielck, das sogenannte Chefarzthaus in der VonAschen-Straße anzumieten. Das Kustodenhaus des inzwischen verstorbenen Paul Kuckuck wurde wieder hergerichtet, und 1918 zog Arthur Hagmeier ein. In das Haus Clemens Hartlaubs, der die Anstalt verlassen hatte, siedelte die Bibliothek um.

Besondere Mühe verwendeten die beiden Direktoren darauf, den ehemaligen Kriegshafen Helgolands zu erhalten und für die Anstalt zu gewinnen. Einzelheiten erläuterten die Gelehrten in ihrer Niederschrift „Zum Ausbau der restlichen Hafenanlagen auf Helgoland als Zufluchtsort für kleinere Seefischerei-Fahrzeuge“. Es ginge, so Mielck, um die Verhinderung der Zerstörung friedlicher Kulturwerke. Das Kultusministerium riet zu langsamem, taktisch klugem Vorgehen, da immerhin die Beschlüsse des Versailler Vertrages dem Anliegen entgegenstanden. Man schlug vor, zuerst den Bau eines sogenannten Wellenbrechers zu beantragen, um fiskalische Fahrzeuge wie die „Augusta“ zu schützen, und den Kriegshafen nicht zu erwähnen. Durch den Wall sollte der Liegehafen der Anstalt geschützt werden, der zugleich als Nothafen für Helgoländer Fischer dienen sollte. Die Helgoländer wehrten sich allerdings gegen diesen Plan. Offiziell beschworen sie eine angebliche Gefahr für ihre Boote infolge des Rückstaus der Dünung an dem Wellenbrecher. Der wahre Grund für ihren Widerstand war jedoch ein anderer: sie befürchteten Konkurrenz fremder Fischer, die diesen nun viel bequemer zu erreichenden Hafen anlaufen könnten. Der Kampf zwischen den Mitarbeitern der Anstalt und dem Kultusministerium einerseits und der Helgoländer Bevölkerung andererseits gestaltete sich zu einer Zerreißprobe. Es nützte nichts, daß Mielck auf alte Pläne des englischen Gouverneurs Maxse verwies, die eine ähnliche Lösung beinhalteten. Von seiten des Kultusministeriums wurde in die Diskussion eingebracht, daß die englische Regierung die Pläne Maxses nur deshalb nicht bestätigt habe, weil England angeblich kein Interesse am Schutze der Insel und ihrer Fischer gehabt habe. Auch eine Besprechung von Vertretern verschiedener Ministerien vom 21--24. 5. 1922 vor Ort blieb ergebnislos. Wie aus dem Protokoll der Besprechung her- 
vorgeht, war der Vertreter des Innenministeriums zum großen Ärger der Repräsentanten des Kultusministeriums geneigt, gegenüber den Helgoländern nachzugeben (38). Die Beamten des Innenministeriums wollten, nachdem die Regierung große Konzessionen gemacht habe, die nun mühsam errungene Beruhigung der Lage auf der Insel nicht aufs Spiel setzen. Man fürchtete, die englandfreundlichen Helgoländer würden sogar wieder beginnen, mit dem „Erbfeind“ Geschäfte zu machen. Deshalb sei eine starke Hand nötig, denn die Einwohner Helgolands seien wie Kinder zu betrachten, die man anscheinend zu ihrem Wohl zwingen müsse und die es einem nachher dankten (38).

In der Folge wurde die Verbindung der Insel zu den deutschen Seebädern bestreikt, und der Staat mußte nachgeben. Mielck und Heincke erreichten jedoch durch zähe Verhandlungen und unter Zugeständnissen an die Fischer, daß von der Ostmole und der Westmole zum Schutze der gefährdeten Düne je ein Stück erhalten bleiben durfte. Dies hatte später Einfluß auf die Anschaffung des neuen Exkursionsfahrzeuges durch die Anstalt.

Die Anstalt erreichte auch, daß ihr auf dem früheren Hafengelände ein $75 \mathrm{~m}$ breiter Streifen vom sogenannten Trossenschuppen (Hafenlaboratorium) bis zum U-Boot-Hafen längs der Nordostmole zur Errichtung von Freilandbecken bereitgestellt wurde. Geplant waren geschlossene Zementbecken verschiedener Größe und Tiefe, die der Fischzucht, der Hummer- und der Austernanzucht dienen sollten. Man wollte die größeren Umfassungsmauern früherer Öltanks nutzen. Man sah vor, durch Errichtung von Stirnwänden aus Betonmauerwerk die Ruinen in abgeschlossene Versuchsbecken von ca. 40 Quadratmetern Grundfläche zu verwandeln. Hagmeier, von dem der Vorschlag stammte, dachte daran, die Tanks durch einfache Eisenrohre mit Sielverschluß ein- und auszulassen. Dabei wollte man auf die von der Anstalt geplante Seewasserleitung für Hafenlaboratorien zurückgreifen.

Es wurden auf Helgoland zwar Freibecken errichtet, aber der größte Teil der Arbeiten zur Austernanzucht wurde in dem 1924 eingerichteten Zweiglaboratorium der Biologischen Anstalt in List auf Sylt durchgeführt. Im Januar 1924 gelang es dem Preußischen Landwirtschaftsministerium, mit der Austernfischerei-Aktiengesellschaft einen Vertrag über die Nutzung eines Gebäudeteiles abzuschließen. Es handelte sich um das Erdgeschoß des sogenannten Arbeiterwohnhauses der fiskalischen Austernanlage in List auf Sylt. Die Möbel hatte die Anstalt vom Marineunterkunftsamt in Sylt geliehen. Die je 1200 Quadratmeter großen Zementbecken wurden für Versuche genutzt. Die Untersuchungen nahmen Kändler und Hagmeier vor. Kändler war in List angestellt. Die Arbeiten auf See wurden z. T. mit dem Austerndampfer der Pachtgesellschaft, „Gelbstern“, z. T. auf dem Dienstfahrzeug der Anstalt, der „Augusta“, ausgeführt.

Die schlechte Finanzlage des Staates hinderte die Leitung der Anstalt nicht daran zu versuchen, auf Helgoland weitere Gebäude zu erwerben. Dazu gehörte das Logierhaus „Stadt Paris“. Der Finanzminister lehnte zunächst ab, lenkte dann aber ein:

„Nur um für ein etwa neu auftretendes staatliches Bedürfnis die nach den besonderen örtlichen Verhältnissen Helgolands seltene Gelegenheit zu einem Grunderwerb nicht ungenutzt zu lassen, will ich zumal im Hinblick darauf, daß sich für die Zwischenzeit auf eine nutzbringende Verwendung des hier fraglichen Hauses im Wege der Vermietung rechnen läßt, der dortigen Anregung nicht von vornherein entgegen sein“ (82).

Es kam allerdings nicht zum Ankauf, da die staatlichen Mittel beschränkt waren. Auch andere Ideen, zum Beispiel das „Deutsche Haus“ zu erwerben, wurden nicht realisiert.

Im Jahre 1921 hielten Mielck und Heincke die Zeit für gekommen, die alten Neubaupläne zu beleben. Sie charakterisierten ihren Plan gegenüber dem Kultusministerium „als Produkt von Gegenwart und Zukunft“. Die baufälligen Teile sollten allerdings zunächst 
notdürftig hergerichtet werden, so zwischen Schauaquarium und Hauptpost. Mielck begründete seinen Antrag mit den Lebensinteressen der deutschen Wissenschaft, zumal die deutsche Meeresbiologie durch den Krieg zurückgeworfen worden sei (34).

Der Antrag wurde genehmigt (35). Das Einverständnis wurde allerdings zwei Monate später wieder zurückgezogen. Der Finanzminister verwies auf die schlechte Lage der Staatsfinanzen, derzufolge sogar die Aufhebung der Anstalt auf Helgoland nach dem vom Staatsministerium beschlossenen Abbauprogramm demnächst zur Erwägung stehen würde. Es wurde mitgeteilt, daß an die Bestellung weiterer Materialien nicht zu denken sei.

Mielck ließ jedoch von seinem Plan nicht ab und bat darum, ausländische Seeaquarien besichtigen zu dürfen. Wie er etwas sarkastisch bemerkte, habe er infolge des Krieges noch keine Gelegenheit gehabt, ausländische Meeresaquarien aufzusuchen. Er beantragte, das kürzlich eröffnete modernste Seeaquarium in London besichtigen zu dürfen, das der Biologischen Station Plymouth, ferner jenes in Neapel. Die Staatsbeamten unterstützten Mielcks Plan. Man beauftragte reisende Wissenschaftler, bei ihren Aufenthalten besonders auf die Aquarien zu achten. Ein Meeresbiologe aus dem Berliner Institut für Meereskunde, der vor seiner Reise nach Woods Hole diesen Auftrag bekommen hatte, teilte ironisch mit, daß amerikanische Verhältnisse keineswegs auf Helgoland übertragbar seien.

Am 24. 10. 1923 lehnte der Preußische Finanzminister den Neubauplan wegen der schlechten Lage der Staatsfinanzen kategorisch ab. Mielck hatte nun die Idee, zwischen "Villa Franz" und dem Aquarium einen Zwischenbau zu errichten. Die „Alte Post" und der "Glashof" sollten abgerissen werden. Die wirtschaftliche Lage besserte sich kurzzeitig, und ab Herbst 1925 konnte mit dem Projekt begonnen werden. Begünstigend für die Bewilligung der Mittel hatte die ernste Drohung des Direktors gewirkt, die Anstalt zu verlassen und Generalsekretär des deutschen Seefischereivereins zu werden. Heincke konnte diese dramatische Entwicklung stoppen, indem er auf die katastrophalen Konsequenzen für die einzige deutsche Meeresstation aufmerksam machte.

Das Projekt wurde mit dem Neubau des Aquariumsgebäudes begonnen. Der Architekt hieß Metzmacher, realisiert wurde der Bau von Baurat Andreas vom preußischen Hochbauamt. Eine Besonderheit war, daß der Bau keine Metallteile enthalten sollte. Sie wurden durch Celluloid, Steingut und Holz ersetzt.

Die Bauarbeiten wurden zum Jahresende durch einen Orkan sehr gestört, der im November 1925 tobte und auf der Insel gewaltige Schäden anrichtete. Dennoch konnte im August des darauffolgenden Jahres der Rohbau fertiggestellt werden. Die angrenzenden Gebäude links und rechts waren jedoch ebenfalls baufällig, und Mielck sah sich veranlaßt, für den Staatshaushalt 1927 Geld für die Fortführung der Arbeiten zu beantragen.

Die Begründung war eine vaterländische:

„Im Zusammenhang mit dem Aquariengebäude und dem jetzt errichteten Zwischenbau wäre somit endlich ein für viele Jahre ausreichender, zweckmäßiger und würdiger Bau für Deutschlands einzige biologische Station geschaffen, so dass sie mit den biologischen Stationen anderer Seestaaten, die übrigens größtenteils mehrere davon haben, auf eine Stufe gestellt werden kann" (83).

Der Antrag wurde genehmigt (84), (85). In den Entwurf des Gebäudes waren jene Erfahrungen und Ideen eingegangen, die Wilhelm Mielck wăhrend seiner Aufenthalte an anderen Stationen, vor allem in Neapel, gemacht hatte. Die Mittel wurden bereitgestellt. Die Außengestaltung war besonders auffällig gewahlt, die roten Klinkersteine waren durch blaurote Fugen abgesetzt. 1927 konnte der erste Teil des Neubaus vollendet und eingerichtet werden. Im Erdgeschoß befand sich das umgebaute ehemalige Schauaquarium. 
Außerdem waren dort eine geräumige Sortierhalle untergebracht, Konservierungsräume sowie Arbeitszimmer für die Anstaltsassistenten, den Oberpräparator und die Verwaltungsbüros. Das neue Schauaquarium füllte das erste Stockwerk aus, außerdem befanden sich dort die Arbeitsräume des Anstaltsdirektors und die Sammlungen. Der zweite Stock war den Abteilungen für Zoologie, für Botanik und den Sammlungszimmern vorbehalten, hier war auch ein über dem Aquarium gelegener großer Raum mit Gastarbeitsplätzen. Im dritten Stock waren ebenfalls Gastarbeitsplätze untergebracht, außerdem die großen Hochbassins aus Holz für die Seewasserzirkulation. Der Keller wurde für Tiefbassins, Maschinen-, Gas- und Heizräume genutzt. Dort befanden sich auch die Laboratorien für Kulturen und Experimente in Dunkelräumen.

Das neue Schauaquarium wurde am 24. 7. 1927 feierlich eröffnet. Nicht ohne Stolz vermerkte Wilhelm Mielck, daß es doppelt so groß wie das frühere sei. Das Portal war sehr schön mit kunstvollen Keramikornamenten aus der Tierwelt des Meeres verziert. Er beschrieb mit großer Begeisterung für Farben und Formen in seinem Bericht die Gestaltung der einzelnen Becken, die zur Eröffnung noch nicht alle eingerichtet waren.

Das am Eingang gelegene Mittelbecken, der größte Behälter des Aquariums, war in Arenaform gebaut und gewährte den „rastlosen Schwimmern des freien Wassers“, Schwärmen von Makrelen, Sandaalen (Spierlingen), Haifischen u. dgl. eine weite und durch Quer-

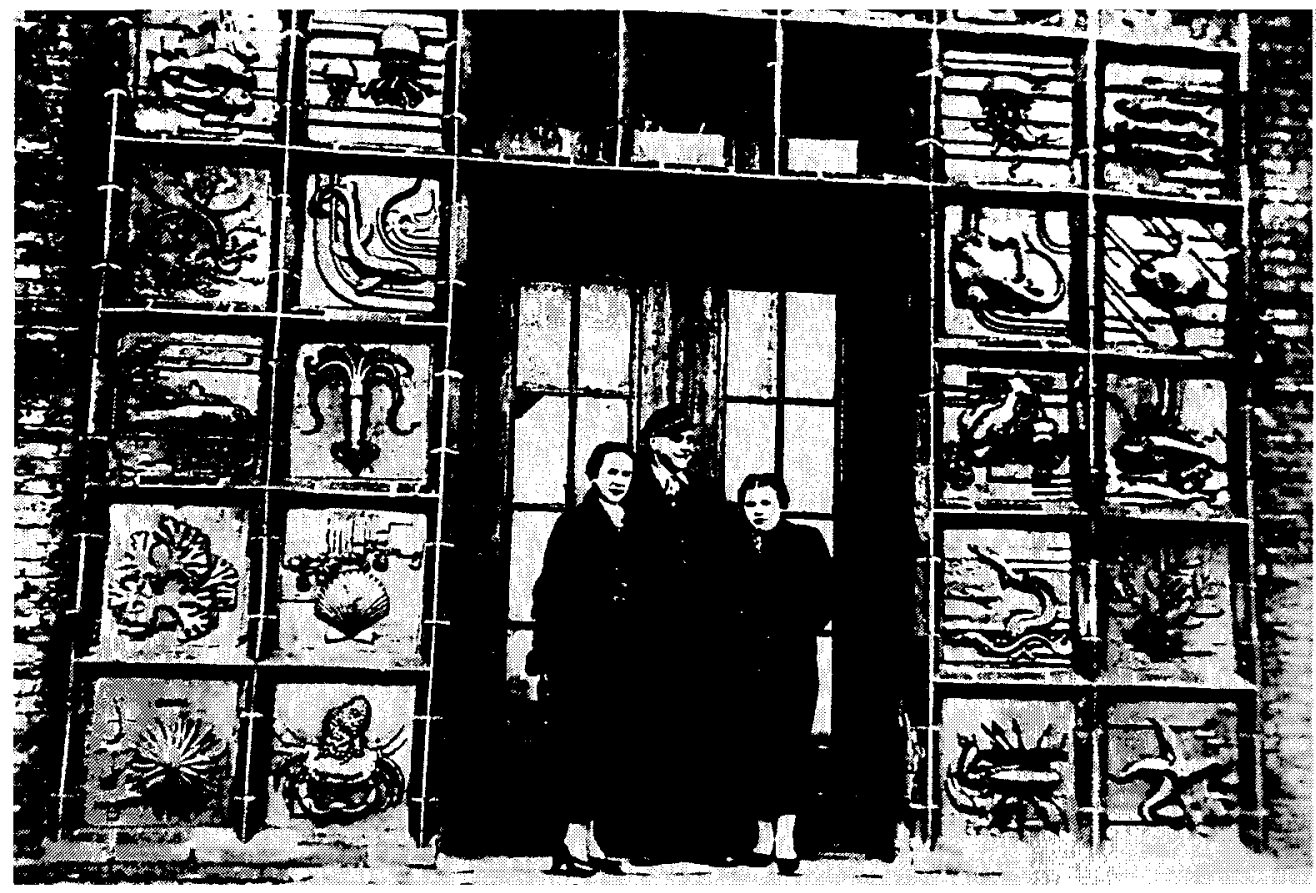

Abb. 25. Eingang zum Erweiterungsbau am Nordstrand, etwa 1938. Sammlung P.H. Sahling. Biologische Anstalt Helgoland. 
wände nicht behinderte Bahn rings um den in der Mitte gelegenen länglichen Bedienungsraum, der eine Wendeltreppe und einen Aufzug für die in wassergefüllten Behältern angelieferten Tiere enthielt. Die für die am Boden des Meeres lebenden Fische typische Schwarmbildung sei, so Mielck, bisher in noch keinem Aquarium gezeigt worden. Im zweiten Becken waren Planktontiere zu sehen, darunter zahlreiche Quallen. An den Wänden des Schauraumes reihten sich große und kleine Becken, die teils einzelne Tier- und Pflanzenarten, teils Proben aus Lebensgemeinschaften zeigten. Die Gestalter des Aquariums hatten sich bemüht, die Tiere möglichst in ihrer natürlichen Umgebung zu zeigen. Sogar Schiffstrümmer hatte man arrangiert, um zu demonstrieren, daß sich sogenannte Seelachse gern in solchen aufhalten. Den Abschluß des Raumes, gegenüber dem Eingang, bildete eine Gruppe von drei großen Becken, die sich durch besondere Schönheit und Farbenpracht auszeichneten. So hatte man den unterseeischen Abfall der Klippe der roten Hauptinsel nachgebildet, bedeckt mit braunen, roten und grünen Tangen, zwischen denen sich Klippenbarsche tummelten. In der Mitte war ein Stück der Nordseereede, mit schwarzem Tökboden bedeckt, nachgebildet, dessen Riffe besetzt waren mit Seenelken, Seeanemonen und Seerosen, den schönen Blumentieren der Nordsee. Das dritte, ebenfalls farbenprächtige Becken stellte die Abhänge der in der Verlängerung der Düne die Nordreede begrenzenden weißen Kreideklippen dar mit den auf ihnen wohnenden Algen und Tieren. Durch den schmalen Ausgang gelangte man in eine durch Ober- und Seitenlicht taghell erleuch-

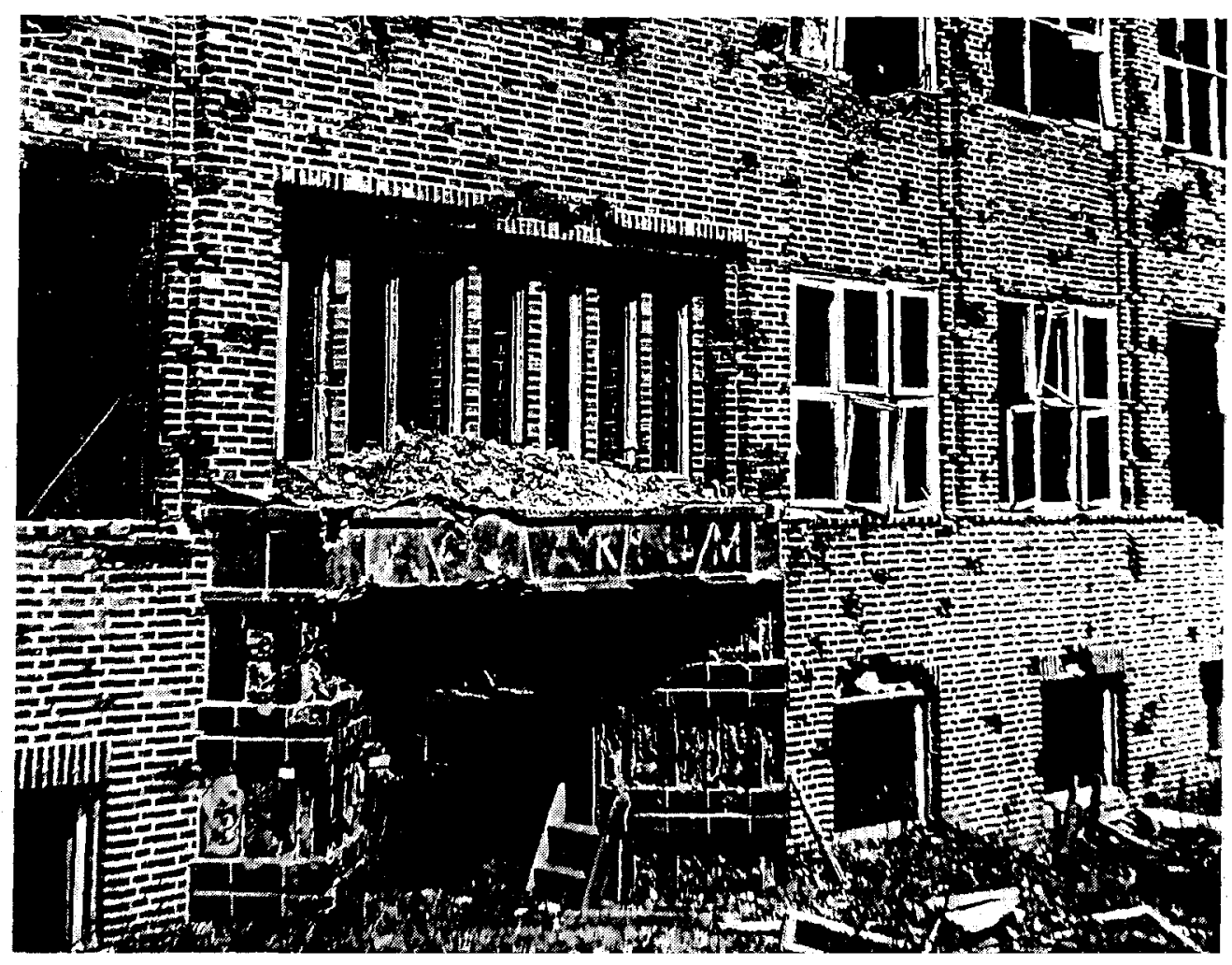

Abb. 26. Die Anstalt (Eingang zum Aquarium) nach dem Bombenangriff auf Helgoland 1945 Foto: Paul-Heinz Sahling, Biologische Anstalt Helgoland. 
tete Halle, in der Seehunde und Lummen, die wichtigsten warmblütigen Tiere der Helgoländer Fauna, zu sehen waren. Die Mitte nahm ein Bassin ein, in dem man die Schwimmbewegungen der Tiere unter Wasser beobachten konnte. Zu beiden Seiten des Bassins befanden sich strandartige Ruhebänke. Den Hintergrund hatte man in Form eines Lummenfelsens gestaltet. Durch die Tageslichthalle an der Seeseite des Gebäudes gelangte der Besucher durch den Schauraum auf einen Balkon (41).

Noch 1927 wurde der zweite Neubauteil begonnen. Er sollte mehrere zoologische Laboratorien für einen bis zwei Forscher enthalten, für Botaniker waren experimentelle und physiologische Labors vorgesehen sowie ein weiteres im ersten Obergeschoß mit Dunkelraum. Chemie und Hydrographie sollten im zweiten Obergeschoß Platz finden, angewandte Meeresforschung im Erdgeschoß. Für geologische Untersuchungen war ein sogenanntes „Geologenzimmer“ im Kellergeschoß vorgesehen. Die Kursräume schließlich sollten nach dem Vorbild der biologischen Station des Museums zu Bergen (Norwegen) eingerichtet werden. Was die technischen Einrichtungen angeht, so war an eine Versorgung der Laboratorien mit fließendem Seewasser und Druckluft gedacht.

Der Bau des zweiten Neubauteiles zog sich bis 1933 hin. Die Bauarbeiten wurden durch die Forderung der Gemeinde, die Bauarbeiten wegen der Lärmbelästigung der Gäste nur außerhalb der Saison durchzuführen, verzögert. Hinzu kam die sich wieder verschlechternde wirtschaftliche Lage, die dazu führte, daß der zweite Gebäudeteil als Rohbau stillgelegt werden mußte. Ab 1931 konnten wieder Mittel bereitgestellt werden, um die Zentralheizung zu installieren, das Dach zu decken und drei Räume des Obergeschosses einzurichten. Im Jahre 1933 war es schließlich möglich, die Bibliotheksräume einzurichten. Diesen Erfolg erlebte Wilhelm Mielck noch mit.

Die weiteren Arbeiten liefen dann unter der Regie Arthur Hagmeiers. 1934 lehnte der Finanzminister die Bewilligung weiterer Mittel für den Ausbau des Neubaus ab. Grundlage waren die mit der Staats- und Verwaltungsreform einsetzenden Sparmaßnahmen. So wurde u. a. vom Direktor der Anstalt mit Schreiben vom 13. 8. 1934 gefordert,

„im Interesse der Gesundung der öffentlichen Finanzen jede Etatsmeldung auf ein unbedingt nötiges Maß (zu) begrenzen" (140).

Bernhard Rust, Reichsminister für Wissenschaft, Erziehung und Volksbildung, beschwerte sich im Namen der Anstalt beim Finanzministerium über diese Entscheidung. Er arbeitete noch einmal drei Punkte heraus, nämlich die Tatsache, daß nach umfangreichen Studien Mielcks in Neapel, Plymouth und Bergen in Helgoland nur die allernötigsten Bedürfnisse einer Meeresstation berücksichtigt worden seien, daß zweitens Deutschland schon jetzt bedauerlicherweise nach dem I. Weltkrieg infolge mangelhafter Arbeitsbedingungen einen Forschungsrückstand erlitten habe, den es aufzuholen gelte. Drittens erinnerte Rust daran, daß Biologie in den Schulen Hauptfach geworden war. Er leitete ab, daß es

„die unabweisbare Pflicht des Staates sein (dürfte, d. V.), dafür zu sorgen, daß dem Nachwuchs in Forschung und Schulbetrieb Gelegenheit geboten wird, die für seine Studien erforderliche Arbeitsgelegenheit zu finden" (114).

Der Finanzminister bemerkte zwar, daß dies wohl nicht ausgerechnet Aufgabe der Helgoländer Meeresstation sein könne, bewilligte aber die Mittel. Später, das sei vorweggenommen, wurden ausschließlich Projekte finanziert, die für das Deutsche Reich als lebensnotwendig betrachtet wurden und der Erfüllung der von Hitler gestellten Aufgaben dien ten.

Noch im Jahre 1935 wurden das dritte Obergeschoß mit dem großen Kurssaal mit Nebenräumen und das Treppenhaus fertiggestellt.

Im Jahre 1938 war das Gebäude endlich vollendet. Inzwischen hatte auf der Insel 
große Wohnungsknappheit eingesetzt, die sich infolge der Vorbereitungen zur „Landesverteidigung" weiter verstärkte. Trotzdem gelang es Hagmeier 1937 ein Wohnhaus auf dem Oberland anzukaufen. Noch 1944 schloß Hagmeier einen Vertrag über den Erwerb der Grundstücke Brodersen und Brust ab, die 608 Quadratmeter umfaßten. Dieser Vertrag sollte 1950 wirksam werden. Das neue Gebäude wurde am 18. 4. 1945 stark beschädigt. Alle Instrumente, der wertvollste Teil der Bibliothek und der Präparate wurden durch Bombenschaden vernichtet. Die zunächst geretteten Aufzeichnungen und Archive gingen durch spätere Plünderungen verloren. Nur Reste von Sammlungen bzw. Möbel, die mit Hilfe der Besatzungsmacht nach dem Festland gebracht werden konnten, waren erhalten geblieben. Am 12. 5. 1945 schließlich wurde die Insel geräumt.

\subsection{Der botanische Versuchsgarten und der Vogelfanggarten}

1905 bat Paul Kuckuck beim Kultusministerium um die Genehmigung, einen botanischen Versuchsgarten auf Helgoland anlegen zu dürfen. Der Garten sollte zur Biologischen Anstalt gehören. In der Begründung erinnerte er an das in der Gründungsdenkschrift und dem Programm erklärte Ziel, botanische Forschungen durchzuführen. Kuckuck wollte zwei Themen bearbeiten: erstens die Erforschung der Landflora Helgolands, zweitens wollte er den Versuch unternehmen, Pflanzen aus anderen Klimaten an Helgoländer Verhältnisse zu gewöhnen.

Was die Erforschung der Landflora anging, so verwies Kuckuck auf die von der Anstalt angeregten Abhandlungen von Paul Ascherson ${ }^{138}$ über Farne (Pteridophyta) und Grünalgen (Siphonales) sowie auf die Arbeiten von Heinrich Sandstede über Flechten (Lichenes). Kuckucks Vorhaben stützte sich auf Messungen, die ergaben, daß die mittleren Temperaturen auf Helgoland weit über denen des Festlandes lagen. Es schien ihm möglich, Pflanzen aus Chile, Neuseeland und Japan zu akklimatisieren, die Feuchtigkeit, Regen und Wind vertragen, aber keine tiefen Temperaturen. Der Boden auf Helgoland, ein sandiger Ton, ist sehr fruchtbar. Um die Bedingungen in Versuchen reproduzieren zu können, wollte Kuckuck jedoch mit künstlichen Bodenmischungen arbeiten. Seine Pläne wurden von zahlreichen Botanikern als sehr interessant befunden, und Direktoren botanischer Gärten aus aller Welt bekundeten ihr Interesse an dem Projekt und boten Unterstützung an. Zu ihnen gehörten Martin Möbius ${ }^{139}$ aus Frankfurt und Hermann Graf zu Solms-Laubach ${ }^{140}$, bis 1907 ordentlicher Professor in Straßburg, aber auch die Direktoren des Botanischen Garten Hamburgs, Berlin-Dahlems, der Scilly-Inseln, Jerseys und Kopenhagens waren an Kuckucks Plänen interessiert.

Neben dem rein wissenschaftlichen Interesse erwähnte Kuckuck auch die Möglichkeit, mittels ausländischer Grassorten die Düne zu befestigen.

Die Kosten für eine erste Einrichtung veranschlagte Paul Kuckuck mit ca. 600 Mark, die jährlichen laufenden Kosten sollten 200 Mark betragen. Auch ein Grundstück hatte er besorgt, die Witwe Magenmann war bereit, ihr Flurstück, das in der Nähe von Kuckucks Wohnung lag, an die Anstalt zu vermieten.

So konnte er 1906 mit der Einrichtung des botanischen Gartens beginnen. Die Pflanzen bezahlte er zunächst aus eigener Tasche. Sein Projekt wurde von Heincke unterstützt, der Mittel für das Jahr 1907 beantragte. Dem Antrag wurden wiederum mehrere Gutach-

138 Paul Ascherson (1834-1913)

139 Martin Möbius (1859-1946)

140 Hermann Graf zu Solms-Laubach (1842-1915) 
ten von Kapazitäten beigelegt, so vom Direktor des Botanischen Gartens Kiel, Reinke, und von Adolf Engler, Direktor des Botanischen Gartens und des Museums in Dahlem (77). Beide befürworteten die Gewährung der beantragten bescheidenen Mittel und boten Hilfe an. Reinke aus Kiel betonte, daß er sich von Kuckucks Untersuchungen Aufschlüsse über die Beziehungen zwischen Klima und Wachstum der Pflanzen erhoffte. Über seinen Kollegen fand er freundliche, anerkennende Worte, indem er betonte,

„daß Herr Prof. Dr. Kuckuck alle von ihm in Angriff genommenen wissenschaftlichen Aufgaben mit Feuereifer und mit eisernem Fleiße durchzuführen pflegt, seine Persönlichkeit also Gewähr bieten dürfte, daß mit dem kleinen Versuchsgarten das Mögliche geleistet werden wird" (76).

Leider wurden die Mittel nicht schnell genug bereitgestellt, so daß Kuckuck wiederum alles aus eigener Tasche verauslagen mußte. Die von ihm geschätzten Kosten wurden allerdings überschritten und betrugen statt 600 Mark etwa 1600 Mark.

In seinem Bericht vom Sommer 1907 präzisierte Kuckuck noch einmal sein Anliegen und ergänzte die Aufgabenstellung. Seine Versuche auf dem 420 qm großen Gelände sollten nicht nur dazu dienen, Pflanzen wärmerer Klimaten anzupassen und Beobachtungen über die Anpassung der Pflanzen an starken Wind durchzuführen, sondern sollten auch der Gemeindeschule für Lehrzwecke helfen (78).

Kuckuck gelang es, das Ministerium für öffentliche Arbeiten und den Regierungspräsidenten von Schleswig für sein Anliegen der Dünenbefestigung zu interessieren. Die preußische Wasserbauverwaltung begrüßte sehr, daß der Botaniker ihnen seine Ergebnisse zur Verfügung stellen wolle, erklärte sich allerdings außerstande, Mittel aus dem Staatshaushalt zur Verfügung stellen zu können. Offensichtlich erwartete man - wie so oft in der deutschen Wissenschaftsgeschichte - in Unkenntnis wissenschaftlicher Forschungsarbeit zuviel von den Kuckuckschen Experimenten und nahm das positive Ergebnis vorweg. Das veranlaßte diesen, vor einer leichtfertigen Übertragung seiner Ergebnisse auf die offene Düne zu warnen. Er sei nicht der Ansicht, daß seine Erfahrungen im Versuchsgarten auf freiliegende Dünen und damit auf praktischen Dünenbau so einfach angewendet werden könnten.

Erst ab 1909 begann Kuckuck mit seinen Experimenten auf der Düne. Wiederum mußte er die Mittel aus eigener Tasche bezahlen. So pflanzte er im Herbst 1909 Strandweizen (Triticum junecum) an die Ostseite vom sogenannten Tathenschen Pavillon. Die Anpflanzungen wurden jedoch während einer großen Sturmflut vernichtet.

1910 erkrankte die Vermieterin des Geländes, auf dem der botanische Versuchsgarten angelegt worden war, schwer. Mit ihrem Ableben mußte gerechnet werden. Kuckuck war in großer Sorge um den weiteren Bestand des Gartens. Das Gelände zu erwerben, erwies sich wegen des hohen Preises als unmöglich. In Abstimmung mit seinem Direktor und dem Ornithologen Weigold (67) stellte Kuckuck den Antrag, einen neuen botanischen Versuchsgarten anzulegen und mit einer ornithologischen Station zu verbinden. Als Gelände schlugen die Wissenschaftler die sogenannte Sapskuhle vor. Dieses Gelände sei groß genug, um durch Anpflanzungen von Buschwerk u. a. ungestörte Rastplätze für Zugvögel und ein ornithologisches Reservat zu schaffen. Die Wissenschaftler schlußfolgerten, daß

„damit die . . E Erhaltung einer der schönsten, jetzt ernstlich gefährdeten Naturdenkmäler Deutschlands der Wandervögelstation Helgoland ermöglicht (wäre, d. V.)“ (79).

Bei der Sapskuhle handelte es sich um ein Flurstück, das bisher als Weideland genutzt wurde. Sie war englisches Kronland und 1893 in preußischen Besitz übergegangen. Das Flurstück war von 1909 bis 1913 an die Gemeinde verpachtet worden, jedoch konnte der Pachtvertrag jederzeit gelöst werden, falls von seiten des Staates Bedarf bestände. Das Königliche Landratsamt machte in einem Bericht den Regierungspräsidenten von Schles- 


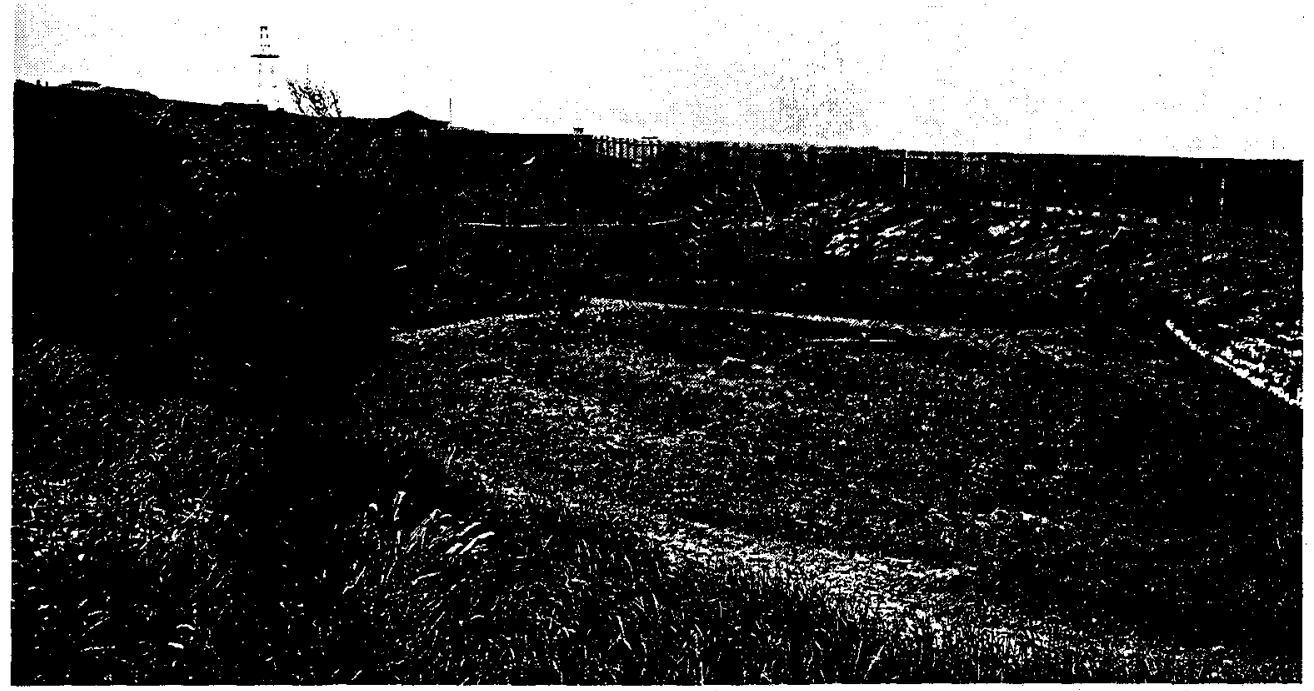

Abb. 27. Der von Paul Kuckuck angelegte botanische und Vogelfanggarten auf dem Helgoländer Oberland (Sapskuhle). Aufnahme um 1912. Archiv der Biologischen Anstalt Helgoland.

wig beiläufig darauf aufmerksam, daß es sich bei der sogenannten Sapskuhle um ein besonderes Stück Gelände handele. Die Sapskuhle sei Schauplatz vorchristlicher Sagen und habe große Bedeutung für die Geschichte Helgolands.

„Dort soll z. B. eine heilige Quelle und ein heiliger Hain sowie alte heidnische Tempel und Opferstätten sich befunden haben“ (80).

Daraus ergab sich eine besondere Beziehung der Bevölkerung zu diesem Stückchen Erde. Tatsächlich sollten sich aus dieser Beziehung im Hinblick auf die künftige Nutzung der Sapskuhle für die Anstalt Probleme ergeben, zumal das Gelände umzäunt wurde und damit als Spielplatz für Helgoländer Kinder wegfiel. Das Landratsamt konnte sich jedoch der Argumentation Weigolds nicht verschließen, daß ein sogenanntes „ornithologisches Naturdenkmal" zu retten sei. Trotzdem wurde betont, daß ihm Ungenauigkeiten unterlaufen seien, die darauf zurückzuführen seien, daß er erst so kurze Zeit auf der Insel sei.

Es gelang Weigold, der über großes Organisationstalent verfügte, vermögende Helgoländer Badegäste zu einer Stiftung für den Vogelfanggarten zu bewegen. Ingesamt kamen 2130 Mark zusammen. Zu den Stiftern gehörte u. a. das Bankhaus Warburg aus Hamburg.

Wie vorausgesehen, behinderten Teile der Helgoländer Bevölkerung die Einrichtung dieses Gartens. Ständig wurde in der kleinen Hütte eingebrochen, und die Leute nutzten in ihrer Verärgerung den Garten als Müllhalde. Das Strauchwerk lockte natürlich auch Kinder an, die in dem Garten umhertobten und die Arbeit behinderten. Mehr als einmal forderte Weigold, das Gelände mit einem $1,80 \mathrm{~m}$ hohen Drahtzaun umgeben zu lassen. Dieses Vorhaben scheiterte jedoch aus Geldmangel. 
Mit dem Beginn des Ausbaus Helgolands zur Festung erwarb die Marine in der Nähe der Sapskuhle zahlreiche Parzellen, um eine katholische Kapelle, ein Offizierskasino, Wohnhäuser u. ä. zu errichten. Ein Problem war, daß sie darauf bestand, auf dem Gebiet der Sapskuhle Wege anzulegen. Das Argument, daß die katholische Kapelle günstig erreichbar sein müsse, überzeugte niemanden, da außer einigen polnischen und italienischen Gastarbeitern, die zum Festungsbau herangezogen worden waren, niemand auf der Insel katholisch war.

Mit Kriegsausbruch wurde der Garten von der Marine beschlagnahmt, kam jedoch schon 1915 - wenn auch völlig verwüstet - wieder an die Anstalt zurück. Bis zum Kriegsende wurde das Gelände als Gemüsegarten genutzt. Nach Kriegsende schilderte Mielck in seinem Bericht, daß bereits mit dem Abzug der Zivilbevölkerung von Helgoland großer Schaden entstanden war, da der Garten das

„von der Zivilbevölkerung in der Not des eiligen Abzuges darbend in ihren Ställen zurückgelassene Vieh, wie Schafe, Ziegen, Schweine, Gänse und Hühner aufnehmen (mußte), die sich die seltenen exotischen Gewächse des Gartens wohlschmecken ließen und in hungriger Gier jedes Blatt und jeden Halm verzehrten, so daß nach wenigen Tagen die ganze Vegetation bis auf die Wurzel abgenagt war" (Mielck 1919).

Mielck vermutete auch, daß die Bevölkerung ihren $\mathrm{Haß}$ auf den Garten in zusätzlichen Verwüstungen Ausdruck gegeben hatte. Allerdings waren die Folgen dann doch nicht so dramatisch, einige Gewächse schlugen unerwartet wieder aus.

Das Kriegsministerium zahlte eine Entschädigung für den Garten, die bei der Anstalt verblieb, da viele Gewächse von Spendengeldern und nicht aus der Staatskasse bezahlt worden waren. Heincke ließ die $2500 \mathrm{Mark}$, die er als Entschädigung erhielt, in Kriegsanleihen anlegen. 1920 wurden 3005,75 Mark ausgezahlt. Die Zerstörung des botanischen Gartens auf Helgoland hatte sowohl in der Fachwelt als auch unter Besuchern und Badegästen großes Aufsehen erregt. Wiederum erklärten sich viele Förderer bereit, neue Pflanzen zu spenden. Bei den Spendern handelte es sich sowohl um interessierte „Hobbybiologen“, insbesondere „vogelkundige Damen“, aber auch Institutionen und Verbände wie der Bund für Vogelschutz, der Bürgerpark Bremen und die Botanischen Gärten Berlin-Dahlem und Bremen.

Die Bemühungen fanden durch den Tod Paul Kuckucks ein Ende. Seine Arbeit wurde nicht fortgesetzt. Hugo Weigold, und während dessen Abwesenheit Arno Marx, richteten die Sapskuhle wieder als Vogelfanggarten her. Allerdings ließen die Spannungen zwischen Anstalt und der Gemeinde nicht nach. Der Gemeindevorsteher forderte mehrfach - wenn auch ohne Erfolg - die Rückgabe des Geländes. Heincke und Mielck handelten einen Kompromiß aus, indem sie den Garten auch Schulkindern zur Verfügung stellten.

\subsection{Schiffe und Flugzeuge der Anstalt}

Die technische Ausrüstung der Anstalt entwickelte sich mit dem Forschungsprogramm. Eine besonders wichtige Rolle spielten die Exkursionsfahrzeuge. Die Anschaffung der Schiffe und Flugzeuge der Anstalt spiegelt eindrucksvoll die wachsenden Bedürfnisse der Institution wider und gibt Zeugnis über technische Neuerungen. Die Anschaffungen waren stets das Ergebnis einer eindrucksvollen Zusammenarbeit zwischen der Leitung der Anstalt bzw. allen Wissenschaftlern einerseits, Staatsapparat und Industrie andererseits. Sie stellen, insbesondere von seiten der Anstalt, organisatorische Meisterleistungen dar. 


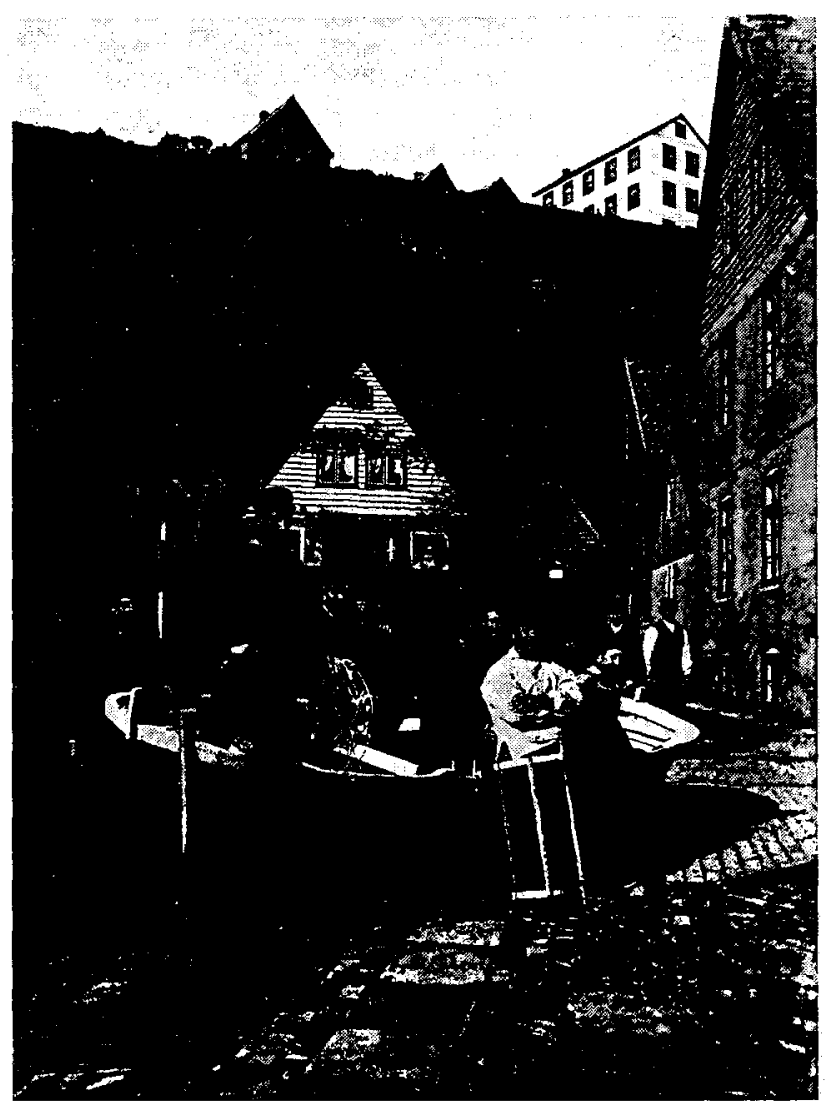

Abb. 28. Fertigstellung des 1. Bootes der Biologischen Anstalt. Dritter von links, Fischmeister Lornsen, zweiter von rechts, Dr. Kuckuck. Archiv der Biologischen Anstalt Helgoland.

Die ersten Boote der Station wurden der Anstalt von der Sektion Küsten- und Hochseefischerei geschenkt. Vermutlich kam diese Schenkung auf Grund der langjährigen Freundschaft Heinckes mit dem Vizepräsidenten des Deutschen Seefischereivereins und späteren Präsidenten Walter Herwig zustande. Es handelte sich um ein ausgedientes, neu lackiertes englisches Fischerboot und ein kleines Boot von Helgoländer Bauart. Schon im ersten Jahr seiner Indienststellung wurde das englische Boot so stark beschädigt, daß sich eine Reparatur nicht mehr lohnte. Heincke beschwichtigte das Ministerium aber im Jahresbericht mit der Versicherung, daß dies der einzige Verlust sei, den die Anstalt bisher zu beklagen habe. Das Helgoländer Börteboot „Bolina“ hingegen erweise sich als sehr gutes Fahrzeug. Während dieser Zeit befand sich das eigentliche Exkursionsboot, eine Barkasse, schon im Bau. Dieses Boot hatte Heincke im Jahre 1892 beantragt, wobei er um Genehmigung eines Petroleummotors für das Fahrzeug bat. Es sollte zu Exkursionen zu den Klippen in unmittelbarer Nähe der Insel benutzt werden und für Fahrten bis etwa 20 Seemeilen von Helgoland entfernt. Es handelte sich um ein etwa 10 Meter langes und 3 Meter breites, als Kutter getakeltes Segelboot mit einem Petroleummotor von 6-8 PS. Das Fahrzeug erhielt den Namen „Augusta“. Darin war immerhin so viel Raum, daß sechs und mehr For- 
scher beim Fangen und beim Sortieren des Materials ausreichend Raum zum Arbeiten hatten (vgl. Flamm 1911). Aber auch mit der „Augusta“ hatte die Anstalt wenig Glück. Bereits ein Jahr nach seiner Anschaffung wurde der Kutter während der Winterstürme fortgetrieben, und die Bergungskosten machten ein Drittel des Wertes aus. Im Jahre 1898 wurden weitere fünf Fahrzeuge angeschafft, darunter vier kleine oder ganz kleine Boote, die von ein oder zwei Leuten gerudert bzw. gesegelt werden konnten.

Bereits seit 1897 gab es Überlegungen, ein leistungsfähigeres Fahrzeug anzuschaffen. Nathanael Pringsheim verwendete sich in einem Schreiben an das Kultusministerium dafür:

„Besonders wünscht Prof. Heincke - und für diesen Wunsch möchte ich mit Wärme eintreten, daß der Helgoländer Anstalt an Stelle des kleinen und nicht ausreichenden Petroleummotors ein mit allen Forschungsmitteln gehörig versehener Untersuchungsdampfer dauernd zur Verfügung gestellt werden möge“ (62).

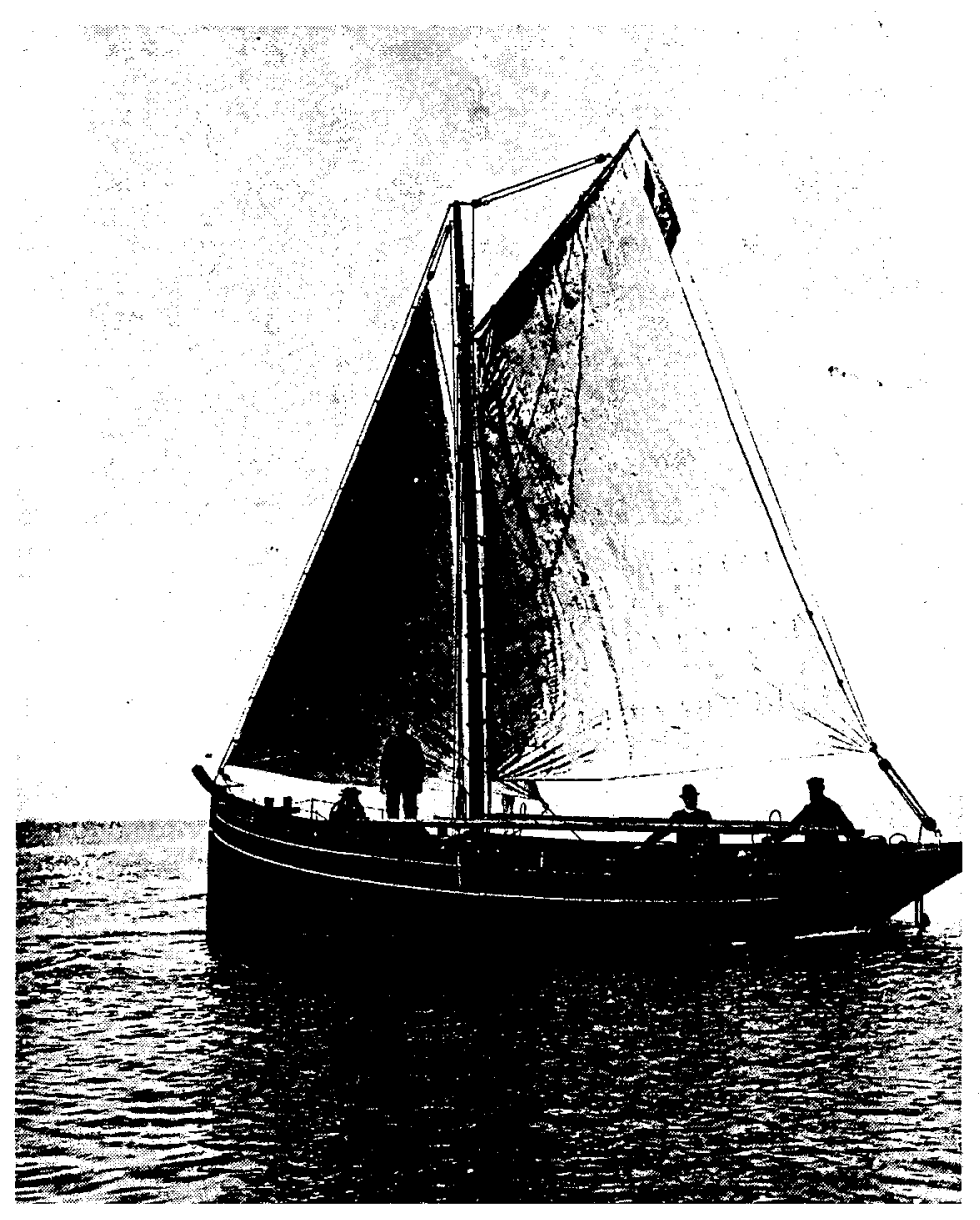

Abb. 29. Die 1893 in Betrieb genommene Kutterschaluppe „Augusta“. Foto um 1900. Archiv der Biologischen Anstalt Helgoland. 
Aber erst 1907 konnte dieser Wunsch erfüllt werden. Ernst Ehrenbaum wurde beauftragt, sich im Anschlu $\beta$ an seine Teilnahme am Kongre $ß$ deutscher See- und Binnenfischer auf der internationalen Motorbootausstellung umzusehen, die im Juni 1907 in Kiel stattfand. Er fand einen deutschen Seekutter H. F. 233 mit verstärktem Benzinmotor aus Dänemark (12). Die Anstalt schlug dem Kultusministerium die Umrüstung des vorhandenen Fahrzeugs nach diesem Vorbild vor. Das Ministerium forderte ein Gutachten von der Königlichen Technischen Hochschule zu Berlin an. Das Gutachten erstellte Oswald Flamm ${ }^{141}$, Inhaber des Lehrstuhls für Theorie und Entwerfen von Schiffen:

„Meine persönliche Ansicht ist die, dass im vorliegenden Falle die Verwendung eines Benzinmotors nicht zu empfehlen ist, wenn auch im Allgemeinen der Benzinmotor vor dem Petroleummotor manche Vorzüge besitzt. Ferner erscheint mir das Richtigste zu sein, den Motor von der Gasmotorenfabrik Deutz zu beziehen, weil mir diese Firma als höchst leistungsfähig bekannt ist und andererseits es doch angebracht ist, bei Lieferungen für den Staat die einheimische Industrie nach Möglichkeit zu berücksichtigen" (13).

Im Jahre 1908 wurde eine nochmalige gutachterliche Äußerung von Flamm eingeholt, weil man erwog, einen Dampfer zu bauen anstelle des vorher geplanten Hochseemotorkutters. Die Idee, einen Hochseekutter zu bauen, hatte man fallengelassen, weil es sich als unmöglich erwies, in Deutschland einen geeigneten Petroleummotor zu beschaffen. Der Kauf eines ausländischen Produkts kam aus politischen Gründen nicht in Frage. Es mußte, so lautete die Vorstellung, ein Petroleummotor mit 20-25 PS für größere Fischereifahrzeuge sein. Die Firma Deutz habe jedoch erklärt, zu einer Lieferung nicht in der Lage zu sein. Flamm wandte sich nunmehr an die Firma Daimler-Motorengesellschaft, die sich unter der Bedingung zur Lieferung eines Motors bereit erklärte, daß Benzin eingeleitet werden dürfe. Ein Benzinmotor wurde jedoch von der Anstalt nicht gewünscht.

Die Verantwortlichen in der Anstalt bestanden auf einem sogenannten Bronsmotor. Die Verhandlungen mit verschiedenen deutschen Motorenfabriken blieben aber ergebnislos, da Deutschland beim Bau von Schiffsmotoren im Rückstand war und keine Firma die Garantie für ein Segelfahrzeug mit Hilfsmotor von 25-30 PS übernehmen wollte. Die einzige Firma, die sich bereit erklärte, den Versuch zu wagen, war die Firma Deutz. Es wurde ein Projekt erarbeitet, das 1910 vorlag. Allerdings war absehbar, daß das vom Ministerium veranschlagte finanzielle Limit erheblich überschritten werden würde. Es kam zu einem Schlagabtausch mit dem Kultusministerium, in dem Heincke etwas ungehalten die vorhandenen Möglichkeiten erörterte, die, wenn kein Geld da ist, folgende seien:

1. den Dampfer kleiner zu bauen, 2. keinen Dampfer zu bauen, sondern einen Motorkutter, 3. ganz zu verzichten. Für den Fall des Verzichts drohte Heincke, die Arbeit der Anstalt einstellen zu müssen:

„... die alte Motorbarkasse („Augusta“, d. V.) der Anstalt genügt nach Größe, Einrichtung und Betriebsart schon lange nicht mehr den allernötigsten Ansprüchen; außerdem ist sehr zweifelhaft, ob sie nach der im Vorjahre vorgenommenen Reparatur überhaupt noch eine weitere ertragen kann, ohne für den Dienst auf Helgoland unbrauchbar zu werden. Jedenfalls muß ich pflichtgemäß darauf aufmerksam machen, daß ich für das ordentliche Weiterfunktionieren dieses alten Dienstfahrzeuges keinerlei Verantwortung mehr übernehmen kann und daß sehr wohl die Möglichkeit vorliegt, daß es eines Tages endgültig dienstunfähig wird und damit die Anstalt plötzlich dauernd ohne Fahrzeug wäre, was ihre ganze Tätigkeit lahmlegen würde“ (18).

Die Situation wurde dadurch verschärft, daß Heincke im Juli 1910 die „Dienst-

141 Oswald Flamm (1861-1935) 
unfähigkeit “ der Barkasse mitteilte (17). Die Diskussion um das neue Fahrzeug wurde wiederbelebt.

Man gab das Motorkutterprojekt auf und entschied sich nun für den Dampfertyp (19). Auch hier entstanden eine größere Anzahl von Projekten, die im wesentlichen ein Fahrzeug von $24 \mathrm{~m}$ Gesamtlänge und etwa 120 PS Leistung betrafen. Es stellte sich jedoch heraus, daß ein solches Fahrzeug zu hohe Betriebskosten verursachen würde, die der Finanzminister nicht bewilligte. Ein Jahr später wurde wieder auf die Motor-Idee zurückgegriffen, jedoch nicht als Hilfsmotor, sondern als Hauptmaschine, während eine kleine Takelage zum Stützen in schwerer See und zum langsamen Laufen vor dem Winde vorgesehen wurde. Auch der Antrieb der Netzwinde sollte vom Motor aus erfolgen.

Im Jahre 1910 konnte ein Vertrag zwischen dem Königlich-Preußischen Fiskus und der Gasmotorenfabrik Köln-Deutz abgeschlossen werden. Es wurde festgeschrieben, daß die Gasmotorenfabrik Deutz die Lieferung eines Dienstfahrzeuges für die Anstalt auf Helgoland übernehme und dasselbe vollständig betriebsfertig nebst Mooring nach Maßgabe der beigefügten Bauvorschrift nebst Inventarverzeichnis und einer der Bauvorschrift angegliederten Beschreibung über die Maschinenanlage abliefern sollte. Das Fahrzeug sollte gute Manövriereigenschaften aufweisen und eine Höchstgeschwindigkeit von sieben Knoten haben, die auf einer zwölfstündigen Probefahrt nachgewiesen werden müßte. Außerdem sollten Maschine und Schraube (verstellbare Flügel) so gebaut sein, daß die Geschwindigkeit bis auf $1 / 2$ Knoten reduziert werden konnte (21).

Schiff und Maschine sollten den Vorschriften des germanischen Lloyd für die Klasse $100 \mathrm{~A} / 4 \mathrm{k}$ (E) und der Seeberufsgenossenschaft entsprechen. Dem Vertrag war als Anlage die Bauvorschrift beigelegt worden. Daraus gehen die Abmessungen des Fahrzeugs hervor. Die Gesamtlänge sollte $24,65 \mathrm{~m}$ betragen, der größte Tiefgang war mit 2,40 m veranschlagt.

Die Kosten sollten $57000 \mathrm{M}$ betragen, zu je einem Drittel zahlbar bei Vertragsabschluß, Stapellauf und Abnahme der vollständigen Lieferung.

Die Firma Deutz übertrug der Firma Stocks und Kolbe in Kiel den Bau des Schiffskörpers mit seinen Einrichtungen. Um in der bewilligten Bausumme zu bleiben, mußte das Fahrzeug verkleinert werden. Die Anlagekosten des Motors waren hoch. Anstelle eines fest eingebauten Behälters zur Aufbewahrung von lebendem Material an Bord, von den Fischern „Bünn“ genannt, wurden an der Steuerbordseite eine Anzahl von Aquarien auf Deck aufgestellt, denen durch eine Kreiselpumpe dauernd frisches Wasser zugeführt wurde. Hinter der Vorpiek und dem Kettenkasten war der Netzraum gelegen, steuerbord die Kammer für den Schiffsführer und den Maschinisten, backbord der Mannschaftsraum. Die Räume wurden mit einem eisernen Kohleofen beheizt.

Was die Möbel angeht, so waren sie im Mannschaftsraum lackiert, im Laboratorium getönt, Schlüssel und Schlösser sowie alle übrigen Beschläge waren selbstverständlich aus Messing und, wie es hieß, von bester Konstruktion. Am Mannschaftsraum befanden sich die Toiletten, einfache Plumpsklosetts. Hinter dem Motorraum lag eine Kombüse. Das mit einem Aufbau über Deck führende Laboratorium war mit einem Sofa, einer Ablage, einem Untersuchungstisch und einem Spülraum ausgestattet. Zur Ausrüstung des Laboratoriums gehörten außerdem: 1 Hängelampe, 2 Stehlampen, die zugleich als Wandlampen benutzt werden konnten, Polster, Kissen, zwei Matratzen, zwei Vorhänge vor den Schlafsofas, Waschtischeinrichtungen mit Spiegel und Fußmatten, zwei waschbare Tischtücher, sechs Mundtücher, vier Feldstühle und eine Trinkwasserflasche mit vier Gläsern. Das Laboratorium verfügte auch über eine spezielle „EBgeschirreinrichtung “, die Kücheninventar und Mannschaftsraumausstattung an Reichhaltigkeit übertraf. Es fällt auf, daß man sich auch auf Alkoholkonsum einrichtete, denn außer sechs Wassergläsern gehörten auch zwölf Wein-, sechs Schnaps- und sechs Biergläser dazu. Darüber, wo sich die Küche 


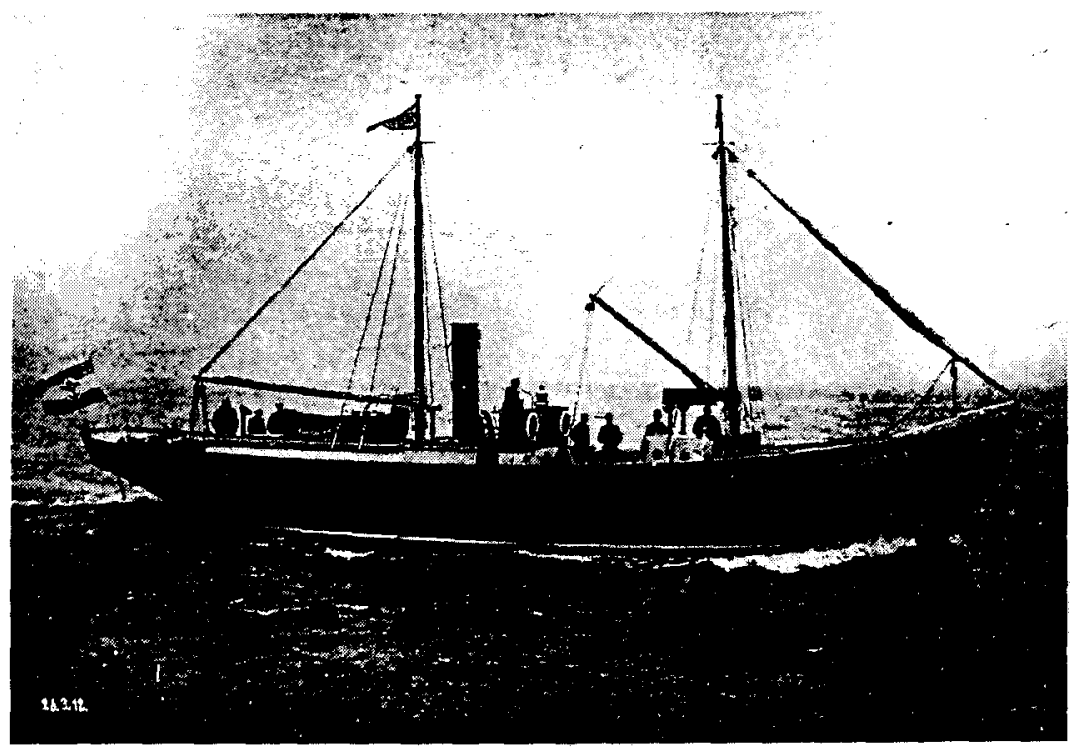

Abb. 30. Das Forschungsschiff der Biologischen Anstalt „Augusta II“ im März 1912, noch mit offenem Führerstand. Archiv der Biologischen Anstalt Helgoland.

befand, wurde nichts ausgesagt. Das Kücheninventar jedoch wurde in allen Einzelheiten aufgeführt. Die Töpfe waren auf zehn Personen ausgerichtet, gekocht wurde auf einem Feuerherd mit zwei Öffnungen. Außerdem stand ein Bratofen zur Verfügung.

Das Schiff erhielt den Namen, Augusta II“. Die Probefahrt am 7. März 1911 fiel nicht zur Zufriedenheit der Besteller aus. Ein Jahr später wurden erneut mehrere Probefahrten durchgeführt, darunter eine zwöfstündige bei schweren Märzstürmen und hohem Seegang zwischen dem 26. 3. und dem 27. 3. 1912. Gutachter Flamm konnte danach dem Minister versichern, daß die vertraglichen Bedingungen nicht nur tadellos erfüllt wurden, sondern die vereinbarte Geschwindigkeit von sieben Knoten bei normaler Belastung sogar um 2,02 Knoten überschritten werden konnte. Das Fahrzeug habe sich in dieser Erprobung, so Flamm, als vorzügliches Seeschiff erwiesen, und insbesondere der Motor habe sich bewährt.

Am 28. März 1912 wurde das Schiff zwecks Besichtigung des Unterwasserschiffs nach der Probefahrt im Torpedobootsdock der kaiserlichen Werft zu Kiel eingedockt und am folgenden Tag nach Helgoland überführt. Die Überführung leitete Fischmeister Lornsen. Er konnte mit Schreiben vom 2. 4. 1912 mitteilen, daß er nach einer schönen Fahrt ohne jegliche Störung der Maschine angekommen sei und das Inventar vollständig vorhanden sei.

Wegen der erhöhten Kosten gab es jedoch Schwierigkeiten. Sie waren zwar mit dem Kultusministerium abgestimmt, jedoch nicht mit dem Finanzministerium. Das Kultusministerium war nun gezwungen, dem Finanzministerium folgendes mitzuteilen:

„Im Hinblick darauf, daß Euere Excellenz, wie auch ich, seinerzeit von der Voraussetzung ausgegangen sind, daß eine Überschreitung der bewilligten Mittel nicht eintreten 


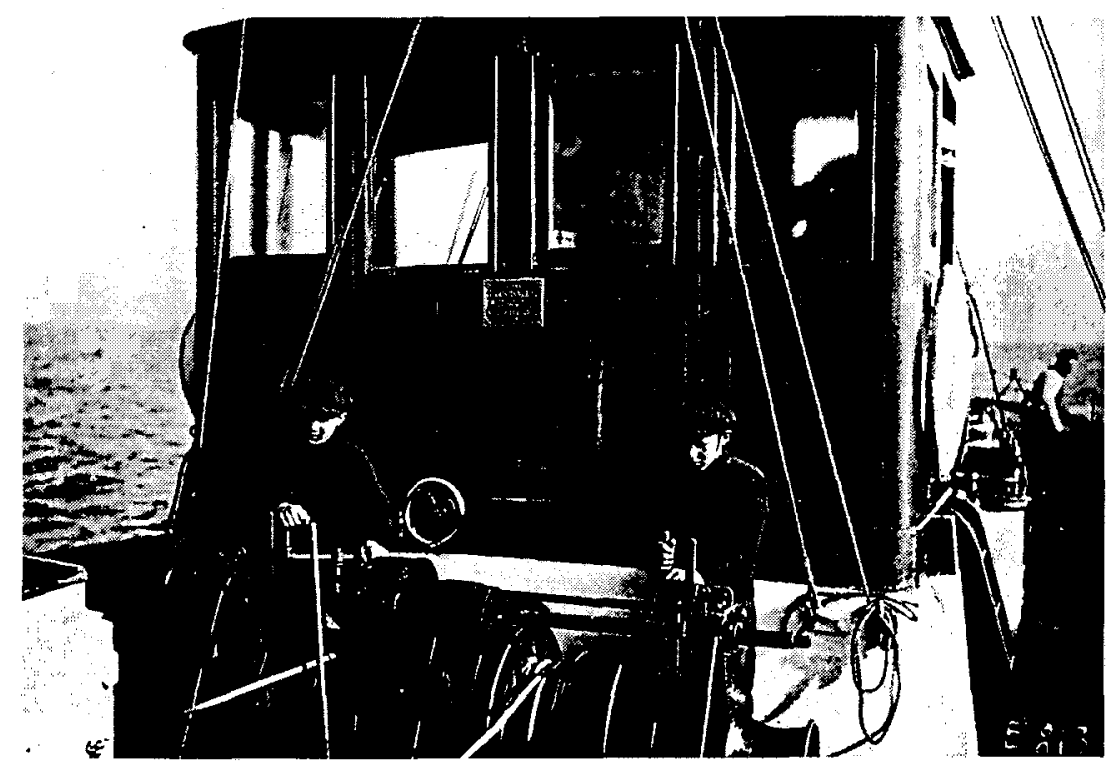

Abb. 31. Augusta II. Vordeck mit Winden. Führerstand nach Umbau geschlossen. Foto: Dr. Pratje 1913, Archiv der Biologischen Anstalt Helgoland.

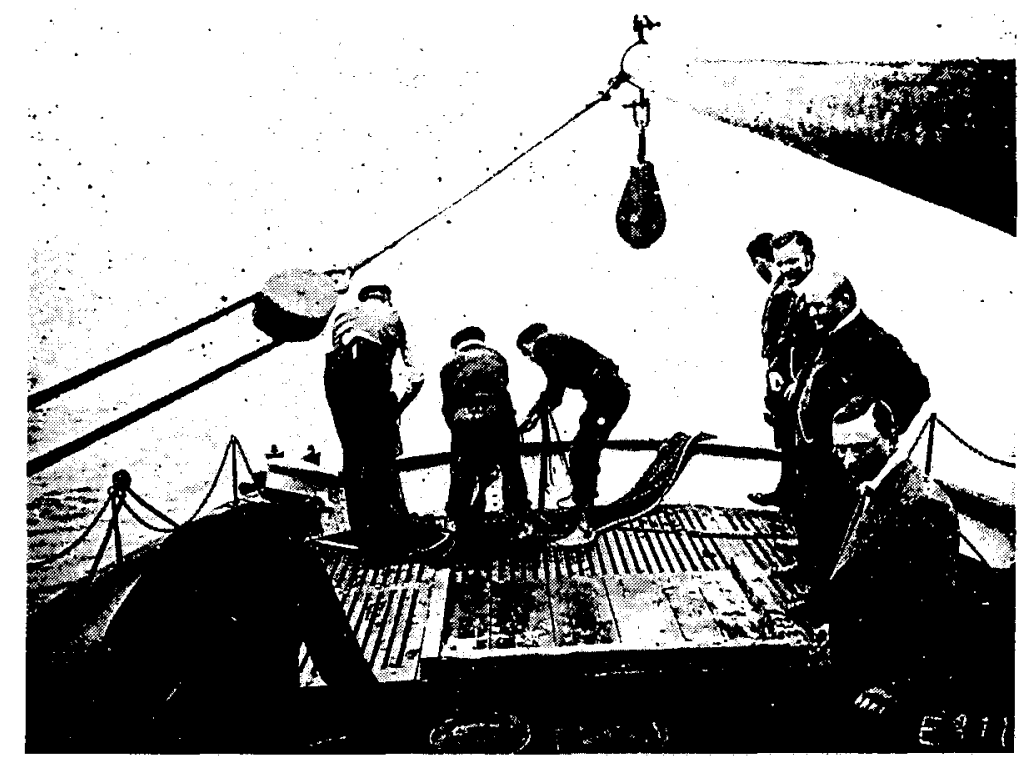

Abb. 32. Augusta II. Die Arbeit an Deck. Foto: Dr. Pratje 1913, Archiv der Biologischen Anstalt Helgoland. 
würde, bedaure ich, daß eine Nachbewilligung sich nunmehr doch als erforderlich herausgestellt hat. Nach Lage der Sache wird dieselbe jedoch keinem der Beteiligten zur Last gelegt werden können“ (108).

Besonders der letzte Satz erregte Mißfallen und wurde vom Finanzministerium mit roten Frage- und Ausrufezeichen verziert. Nach längeren Diskussionen wurde jedoch gezahlt.

Bereits im August 1914 wurde das Schiff militärisch besetzt und fungierte als Wachboot bzw. für Transporte zwischen Festland und Insel. Es sei daran erinnert, daß es üblich war, Fischereifahrzeuge als Wachboote einzusetzen. Während des I. Weltkrieges wurden 120 solcher Fahrzeuge versenkt. Wilhelm Mielck, Oberleutnant der Reserve und II. Adjutant der Kommandantur von Helgoland, wurde beauftragt, den Befehl und die Aufsicht über die Mannschaft der „Augusta II“ zu übernehmen. Im November 1914 konnte es jedoch wieder an dịe Station zurückgegeben werden. Hier erfüllte das Boot seine Doppelfunktion als Forschungs- und Fischereiboot hervorragend.

Die gefangenen Speisefische wurden, soweit sie wissenschaftlich nicht verwendet werden konnten, an die Küchen der einzelnen Truppenteile der Festung und der von Helgoland aus operierenden Kriegschiffe (Unterseeboote, Torpedoboote usw.) verschenkt. Als die Nachfrage mit der steigenden Lebensmittelknappheit zunahm und immer mehr Fahrten und Fischzüge gemacht werden mußten, die den zur Verfügung stehenden Etat überschritten, wurde mit Genehmigung des Ministers eine sogenannte Fischkasse eingerichtet. In diese Fischkasse flossen die Einnahmen aus der „Kriegsfischerei“. Daraus wurden die Aufwendungen beglichen, und Führer und Mannschaft erhielten als materiellen Anreiz einen prozentualen Anteil am Erlös. Von den zwischen 1915 und 1918 erwirtschafteten Einnahmen verblieben $40000 \mathrm{Mark}$, die für besondere Zwecke zur Verfügung standen. Sie waren später der Grundstock für die Einrichtung des nach Wilhelm Mielck benannten Studentenwohnheimes. Nicht verbrauchte bzw. verkaufte Fische wurden mittels verschiedener Methoden konserviert, so unterrichtete Aquarienwärter Holtmann die Militärs darin, Fische mittels Räuchern, Salzen und Dörren zu konservieren. Auf der Insel entstanden nach und nach sechs vollständig eingerichtete Räuchereien, eine Gesellschaft zur Herstellung von Fischkonserven und zahlreiche kleine und kleinste Einzelbetriebe. Die Helgoländer versorgten Freunde und Verwandte auf dem Festland mit Fisch, so sollen angeblich manchmal mit einer Postsendung mehr als 1000 Fischpakete in alle Gegenden Deutschlands verschickt worden sein.

Die „Augusta II“ war bis ca. 1935 im Dienst. Sie wurde 1937 an die SA verkauft, nachdem das Ozeanographisch - Biologische Institut in Split vom Kauf zurückgetreten war. Ab 1931 bereitete die Instandhaltung des Schiffes größere Mühe, und es mußten inzwischen immer wieder Anträge auf Instandsetzung gestellt werden. Zwischendurch war ein kleineres Motorboot „Ulrich“ angeschafft worden, dessen einzylindriger Motor sich jedoch als zu schwach erwies, stark vibrierte und nur geringe Geschwindigkeiten zuließ.

Im Januar 1934 sah sich der um ein Gutachten zum Zustand der „Augusta II" gebetene Schiffsbaudirektor gezwungen, das Finanzministerium in einem Schreiben nochmals auf die große Verantwortung hinzuweisen, die das Ministerium mit der weiteren Indiensthaltung der „Augusta II" auf sich nehme (118). Trotzdem lehnte der Finanzminister auf Grund der katastrophalen Lage der Staatsfinanzen einen Neubau ab. Dem stand gegenüber, daß das Schiff "Augusta II" jährlich ca. 3000 RM an Instandhaltungskosten verursachte.

Etwa ab 1935 wurden mehrere Angebote von Schiffswerften zum Neubau eingeholt. Voraussetzung war wiederum, eine deutsche Werft zu wählen. Bitten der Werften, das Angebot zu bekommen, um Arbeitsplätze zu erhalten, kam man nicht nach. Das einzige 
Kriterium war der Preis. Der Zuschlag wurde an die Schiffsbaugesellschaft „Unterweser A. G. in Wesermünde "gegeben, die alle Angebote unterboten hatte.

Wie in früherer Zeit erwies sich die Leitung der Anstalt als experimentierfreudig und entschied sich für eine Neuerung, den Voith-Schneider-Propeller (V. S. P.), und einen dieselelektrischen Antrieb. Arthur Hagmeier, inzwischen Direktor der Anstalt, begründete seinen Wunsch gegenüber dem Ministerium so:

„Die Bedeutung des neuen Antriebs für die deutsche Wirtschaft wird auch hier günstig beurteilt. Bei erfolgreicher Einführung wird sich sicher die Möglichkeit des Exportes ergeben" (120).

Der Hinweis auf in Aussicht stehende Exportmöglichkeiten erhöhte die Chance des Antrages gewaltig, da Deutschland an Devisenmangel litt. Um den Devisenverbrauch zu kontrollieren, war mit Wirkung vom 18. 12. 1934 ein Gesetz über die Schaffung einer Reichsstelle für Devisenwirtschaft in Kraft getreten.

Der Bau des Schiffes wurde bewilligt. Es erhielt den Namen „Makrele“. Allerdings gab es mit der Neuerwerbung ständig Schwierigkeiten. So war die Kursstetigkeit mangelhaft. Schließlich gelangte sogar Seewasser in den Propellerraum, und der Umsteuerungsknüppel rostete fest. Hagmeier konstatierte verärgert, daß

„diese Erscheinungen zeigen, daß an der Konstruktion des V. P. S. für Seeschiffe noch weiter gearbeitet werden muß und es . . bedauerlich (ist, d. V.) daß gerade das Dienștfahrzeug der Anstalt das Versuchsobjekt für die Weiterentwicklung des V. P. S. sein mußte" (119).

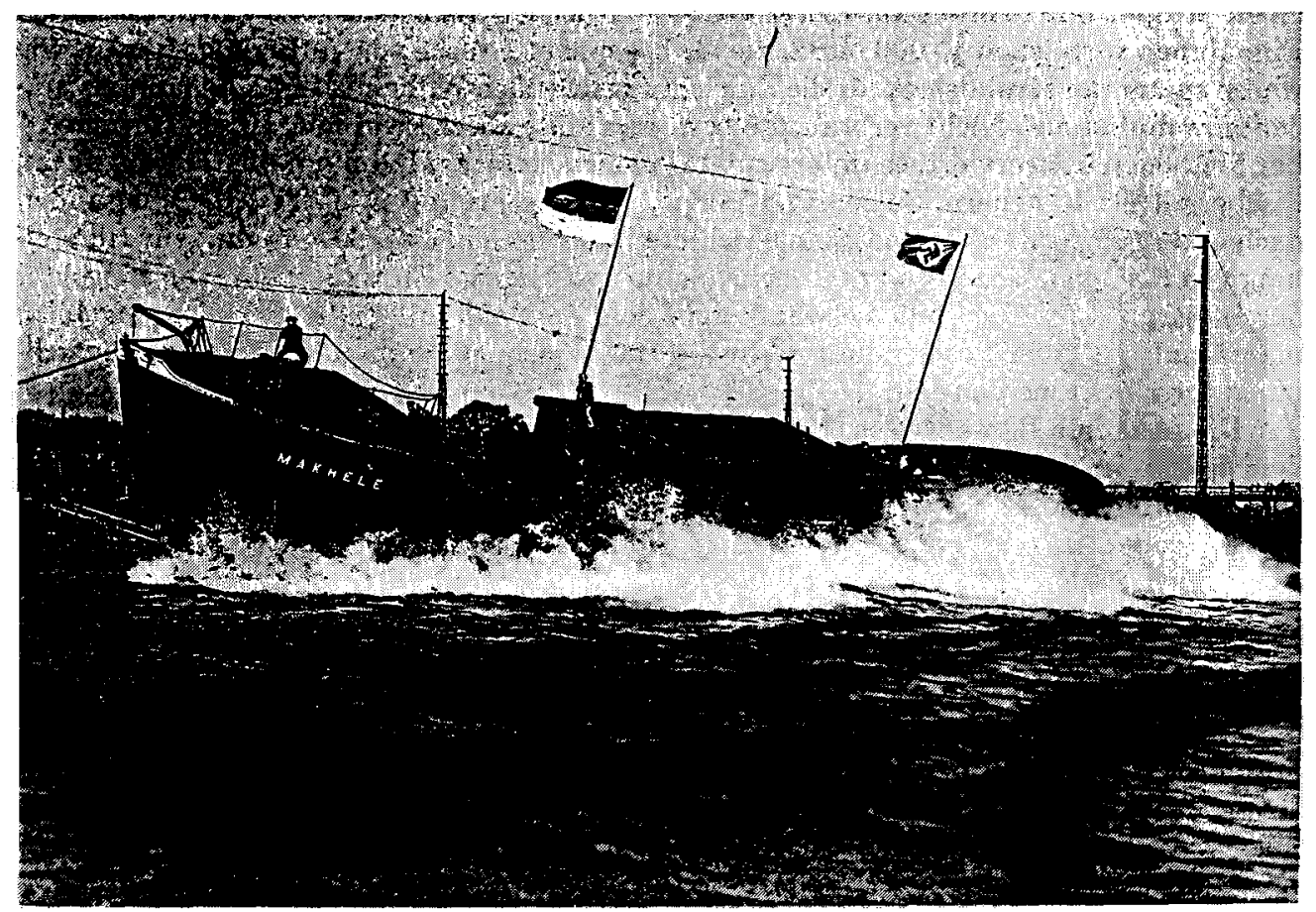

Abb. 33. Stapellauf des Forschungschiffs Makreles der Biologischen Anstalt am 17. September 1936 Foto aus dem Nachlaß von Prof Meyer-Waarden. Archiv der Biologischen Anstalt Helgoland. 


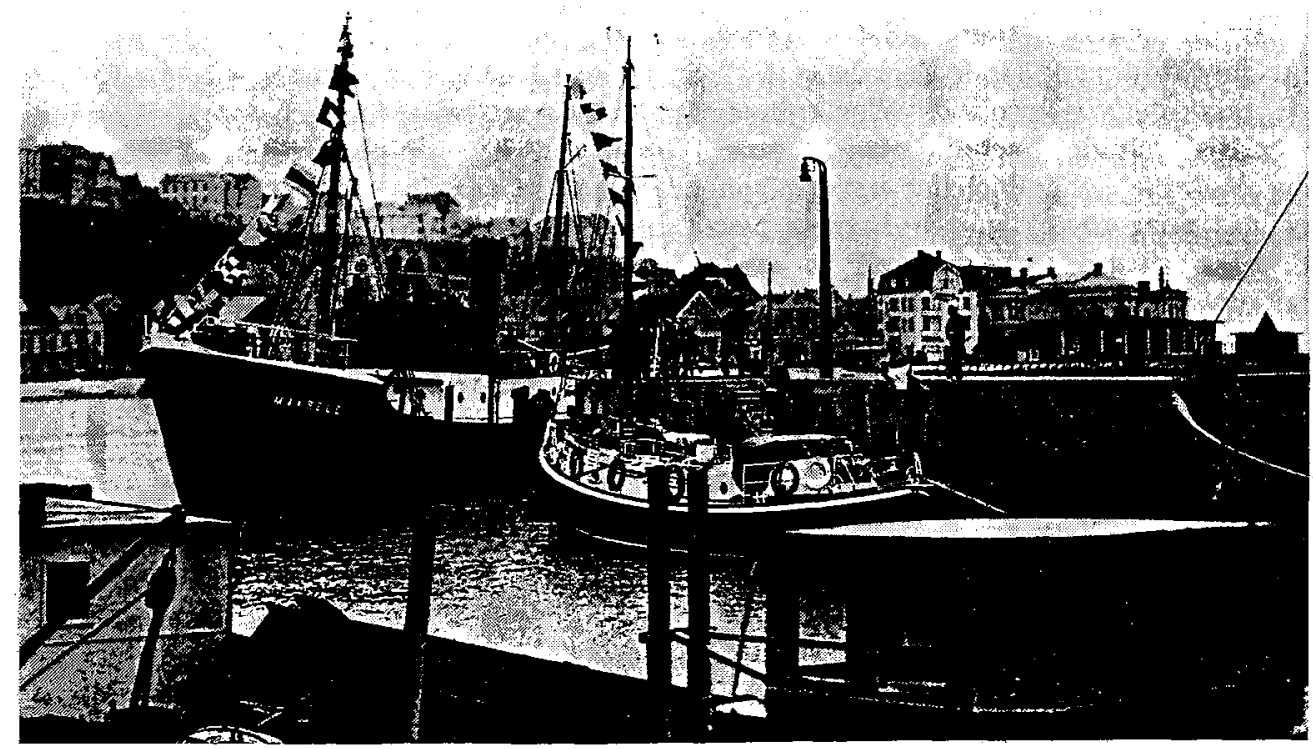

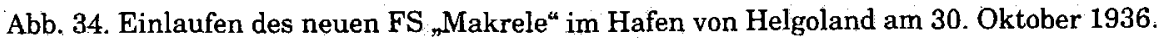

Foto: Franz Schensky.

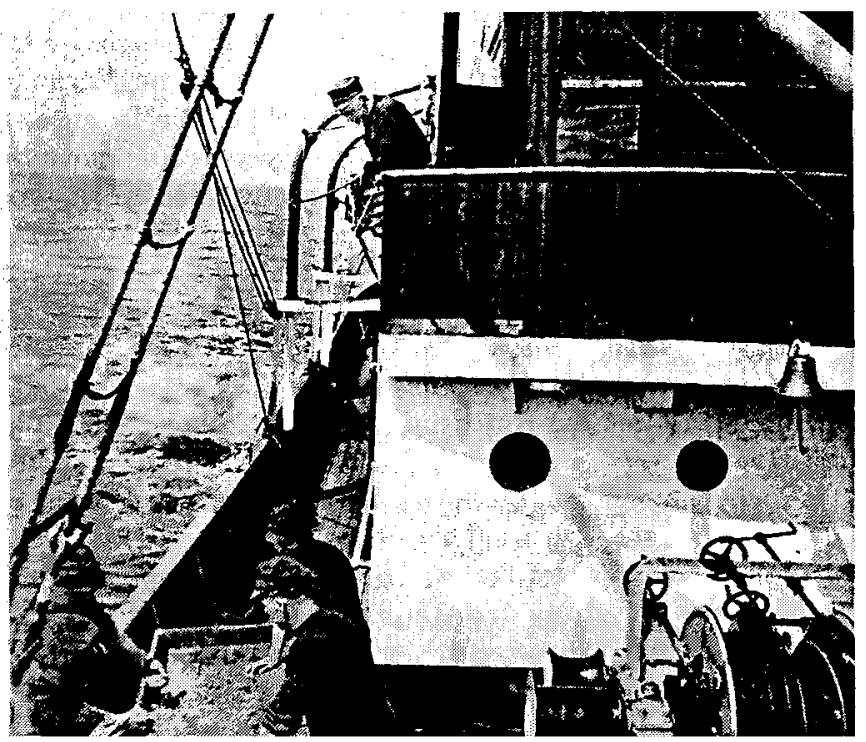

Abb. 35. Auf der Brücke der "Makrele“ Jacob Peter Holtmann (1887-1962), Mitarbeiter der Anstalt ab 1902. Er führte die „Augusta II" als Kapitän, später die "Makrele" und begründete eine bis heute ununterbrochene Familientradition im Dienste der Anstalt. An Deck werden Lanzettfischchen aus dem Sand aussortiert. Foto: H. Dietze, 1938 Archiv der Biologischen Anstalt Helgoland. 
Die weitere Verbesserung verursachte schon 1937 Zusatzkosten in Höhe 15154 RM. Fritz Horn ${ }^{142}$ von der Technischen Universität Berlin, ordentlicher Professor mit Lehrstuhl für Dynamik von Schiffen und Vorsteher der Versuchsanstalt für Schiffsbau, arbeitete in einem Gutachten heraus, daß die Werft den Vertrag nicht erfüllt hatte (120). Er plädierte für die Einführung einer Heckflosse. Es begann eine Diskussion darüber, wer die Kosten zu tragen habe. Obwohl die Werft eindeutig Schuld war, bekannte sich das Ministerium zum Risiko in der Technikentwicklung und erklärte sich bereit, die Kosten zu tragen, da die „Makrele“ schließlich das erste tiefgehende Seeschiff war, das mit Voith-Schneider-Propellern ausgerüstet war. Außerdem besaß man so viel Erfahrung einzusehen, daß ein Rechtsstreit mit der Werft erfolglos verlaufen würde. Nach einem Erfahrungsaustausch mit einem Räumboot R 20 der Kriegsmarine erreichte man schließlich, das Schiff so umzukonstruieren, daß die Strecke Helgoland/List, also 65 Seemeilen, in $63 / 4$ bis 8 Stunden zurückgelegt werden konnte. Das Schiff erwies sich jedoch als äußerst anfällig, ständig mußten Reparaturen durchgeführt werden. So wurde es im August 1940 nötig, eine Reibungskupplung im Wert von $3600 \mathrm{RM}$ zu ersetzen.

Ebenso wie die „Augusta II" hatte das Forschungsschiff "Makrele“ die Aufgabe, Seefische für die „Volksernährung“, wie es hieß, zu beschaffen. Demzufolge war es, wie Hagmeier anmahnte, auch im Kriege von Wichtigkeit, daß das Dienstfahrzeug stets einsatzbereit war.

Es gab in der Geschichte der Anstalt auch einen sehr frühen Versuch, den Aktionsradius zu erweitern und einen Teil der Forschungsarbeiten aus der Luft durchzuführen. Es war Hugo Weigold, der diese Idee hatte. Es gelang ihm, noch 1913 Friedrich Heincke dazu zu veranlassen, einen Antrag an das Kultusministerium zu richten, das Reichsmarineministerium um Mithilfe zu bitten. In einem späteren Bericht erläuterte Heincke, warum er das Flugzeug als Forschungsmittel für so wichtig hielt. Erstens erhoffte er sich eine leichtere und bessere Möglichkeit, hydrographische und fischereizoologische Untersuchungen durchzuführen (Muschelbänke, Wanderung der Heringsschwärme, Veränderung des Meeresgrundes und ihre biologischen Folgen). Zweitens sah er die Chance, ornithologische Untersuchungen durchzuführen, z. B. Vogelschwärmen, wie es Heincke ausdrückte, in alle Höhen und Tiefen zu folgen. Um zu prüfen, ob das Flugzeug tatsächlich ein geeignetes Forschungsmittel für die Anstalt sei und sich seine Anschaffung lohne, wollte Hugo Weigold zunächst die Flugzeuge der Marine ausprobieren. Heincke stellte einen derartigen Antrag. Er verbürgte sich dafür, daß sein Mitarbeiter keinesfalls ein Sicherheitsrisiko für den preußischen Staat darstelle, habe er doch jahrelang Zugang zu militärischem Sperrgebiet gehabt und sei auch in Messungen einbezogen worden.

Das Reichsmarineamt teilte dem Kultusministerium trotzdem bedauernd mit, so der Stand vom 19. 9. 1913, daß eine Teilnahme des Vogelkundlers Weigold an Flügen des Marine-Luftschiffes nicht möglich sei, da dieses Gefährt mit militärischen Aufgaben ausgelastet sei (68). Die Marine sei jedoch angewiesen worden, alle interessanten Beobachtungen über den Vogelzug auf der Nordsee zu sammeln. Die Versuche mit ausgestopften Vögeln könnten jedoch nach Anleitung der Marineangehörigen durchgeführt werden. Wie aus späteren Berichten Heinckes hervorgeht, konnte Weigold dank des Entgegenkommens der Nordseefliegerei-Abteilung in zwölf Einzelflügen ausprobieren, ob das Fluggerät wirklich für Forschungsaufgaben geeignet war. Vermutlich geschah dies schon 1913. Seine Beobachtungen veröffentlichte er 1920 in der Ornithologischen Monatsschrift unter dem Titel „Fliegerbeobachtungen. Über die Höhe des Vogelfluges“. Was die ersten erwähnten

142 Fritz Horn (1880-1972) 
Versuche angeht, so handelte es sich um Weigolds Idee, ausgestopfte Vögel aus dem Flugzeug heraushängen zu lassen. Damit wollte er prüfen, in welcher Höhe die scharfäugigen Helgoländer die Vögel noch sicher identifizieren können. Die Versuche dienten also der Überprüfung empirischer Untersuchungen. Bemerkenswert ist Weigolds Einschätzung, daß das Flugzeug gegenüber dem Lenkballon natürlich gewisse Nachteile habe, als praktisches, handliches und relativ billiges Mittel aber schon einen großen Fortschritt bedeute.

Nach dem I. Weltkrieg nahm Heincke mit dem Verweis auf die interessanten Vorversuche Weigolds die Bemühungen wieder auf, für die Anstalt Seeflugzeuge zu bekommen. Er hielte es im Interesse der reinen und der angewandten Wissenschaften für dringend erwünscht, daß bei der von der Entente verlangten Vernichtung oder Auslieferung sämtlicher Marineflugzeuge einige für die „rein kulturellen Zwecke“ der Anstalt erhalten blieben. Diese Anstrengungen waren Teil der Bemühungen, nach dem verlorenen Kriege mit Hilfe von Marinebeständen (Gebäude, Hafen usw.) die Arbeitsmöglichkeiten der Anstalt zu verbessern. Heincke erwies sich bei der Vertretung seines Anliegens als sehr hartnäckig. Er sandte entsprechende Telegramme an die Admiralität in Berlin, den Reichsernährungsminister und den Minister für Wissenschaft, Kunst und Volksbildung. Die Antwort der Admiralität fiel negativ aus. Unter Hinweis auf die Konferenz von Spa wurde Heinckes Anliegen, Seeflugzeuge aus Marinebeständen zu retten, als aussichtslos abgetan. Unterstützung erhielt der Direktor hingegen vom Reichsernährungsminister. Es entspann sich ein langer Brief- bzw. Telegrammwechsel zwischen verschiedenen Behörden, auch die Frage eines Scheinkaufs wurde überlegt (26).

Das Kultusministerium zeigte sich - wie schon in der Hafen-bzw. Gebäudefrage - sehr kooperativ. Am 9. 8. 1920 befürwortete das Reichsamt für Luft- und Kraftfahrwesen den Erwerb von zwei Wasserflugzeugen. Die Genehmigung wurde von der Alliierten Überwachungskommission der Entente erteilt, allerdings wurde vorgeschrieben, daß die technische Leistung der beiden Seeflugzeuge 260 PS nicht überschreiten dürfe.

Im Oktober 1920 wurde Heincke informiert, daß keine Wasserflugzeuge (Typ Albatros) vorhanden seien. Es wurde angefragt, ob die Anstalt auch mit Landflugzeugen als Behelf vorlieb nehmen würde. Dieses Angebot wurde angenommen, und von der Reichstreuhand wurden zwei Flugzeuge freigegeben. Am 2. 4. 1921 erging von der Allgemeinen Luftfahrtkommission die Anweisung, der Anstalt zwei Doppeldecker unentgeltlich zu überlassen. Nun begannen längere Verhandlungen darüber, die Flugzeuge gegen wirklich brauchbare Maschinen auszutauschen. Angestrebt wurden Doppeldecker der Firma Luftverkehrsgesellschaft Johannisthal in Berlin (L. V. G.). Die Übernahme der beiden Flugzeuge (12033/ 18 und 9074/18) erfolgte am 19.4. 1921 durch einen englischen Piloten und einen Flugzeugführer der Polizeifliegerstaffel Lübeck. Die Flugzeuge sollten nach Bremen überführt werden, um dort untergestellt zu werden. Wie aus dem Übernahmeprotokoll hervorgeht, verunglückte eine Maschine bei der Übernahme, der Berichterstatter betonte jedoch, daß er sich trotz seiner schweren Verletzungen noch am Unfalltage bemüht habe, Ersatz für das abgestürzte Flugzeug zu organisieren. Der verbliebene „Aufklärer“ L. V. G. C- IV wurde in Bremen untergestellt, war aber nur geeignet, über den Watten bis zur Inselkette hin Untersuchungen durchzuführen (32). Für den abgestürzten „Aufklärer“ konnte kein Ersatz beschafft werden, lediglich eine Fokker D VII, das leistungsfähigste Jagdflugzeug des I. Weltkrieges, war lieferbar. Die Anstalt entschloß sich, das Flugzeug zu erwerben. Die Mitarbeiter der Anstalt hatten nun die Idee, mit dem Meteorologischen Observatorium Bremen zusammenzuarbeiten, um das Hauptproblem, die Wartung der Maschinen, zu lösen. Die zweite Schwierigkeit waren die hohen Unterhaltskosten. In dieser Frage wollte man mit dem Meteorologischen Observatorium Bremen zusammengehen. Sowohl das KuItusministerium als auch das Reichsernährungsministerium erklärten sich bereit, Betriebs- 
mittel zu übernehmen. Weigold beantragte vorerst 60000 RM Betriebsmittel für das Haushaltsjahr 1921/22 und begründete seinen Antrag politisch:

„Mit Rücksicht auf die Finanzlage des Reichs ist das Programm sehr beschränkt, aber man darf den Hauptgesichtspunkt nicht aus dem Auge verlieren, daß unser deutsches Flugwesen jetzt seine schlimmste Krise durchmacht und es eine der vornehmsten allgemeinen Kulturaufgaben ist, daß die Wissenschaft als die berufenste und nach dem Friedensvertrag beinahe einzige dazu fähige Helferin einspringt. Wie für den Verkehr so eröffnet das Flugwesen auch für die ... Wissenschaft die größten Fortschrittsmöglichkeiten, die für den internationalen Ruf und die Wiederzulassung Deutschlands von allergrößtem Propagandawert sind" (33).

Gleichzeitig warnte Weigold davor, bei dem geringen Umfang der beantragten Betriebsmittel allzu große Erwartungen zu hegen. Es ginge lediglich darum, so lautete eine der berühmten poetischen Wendungen Weigolds, das mit Mühe geschliffene Werkzeug deutscher Wissenschaft „deutsches Luftverkehrswesen“ nicht aus der Hand zu geben und im Gegenteil dafür zu sorgen, daß es wieder jene Stellung erhalte, die ihm gebühre.

Das Luftfahrtministerium sollte der deutschen Wissenschaft wieder zu internationalem Ansehen verhelfen und sie aus der internationalen Isolierung herausführen. Die Mittel wurden bewilligt, aber die Anstalt sah sich genötigt, die beiden Flugzeuge an das Preußische Aeronautische Observatorium in Lindenberg (Mark Brandenburg) zu übergeben, da sie von den Wissenschaftlern nicht gewartet werden konnten. Die Fokker D VII kam 1927 an die Anstalt zurück, allerdings ohne Motor, der verschlissen war. Weigold verließ die Anstalt, und für Mielck ergab sich die große Schwierigkeit, ein Forschungsprogramm zur Verwendung der nun bewilligten Mittel einzureichen. Die Tatsache, daß ein halbes Jahr später noch immer eine ausweichende Antwort kam, verstimmte natürlich den Reichsminister für Ernährung und Landwirtschaft, wie aus einer Mitteilung an den Kultusminister eindeutig hervorgeht.

Spätestens ab 1926 wurde der „Aufklärer“ von Weigolds Nachfolger Rudolf Drost genutzt, der 1927 einen ausführlichen Bericht über seine Arbeit vorlegte (40) und zahlreiche noch nötige Untersuchungen in Aussicht stellte. Im Mittelpunkt seiner Arbeit standen die Erforschung des Vogelzugs und systematische Fragen des Vogelschutzes. Nun wurde das Flugzeug in Norderney untergestellt. Bestrebungen, die Landmaschine gegen ein Seeflugzeug zu tauschen, scheiterten vor allem deshalb, weil ein brauchbares Seeflugzeug viel teurer gewesen wäre. Mielck teilte 1928 mit, daß die beiden Maschinen veraltet und unbrauchbar seien, der noch in Betrieb befindliche „Aufklärer“ ließe sich aber vielleicht gegen das Großflugzeug R K 9 „Grasmücke“ vertauschen. Mit großer Mühe fand die Anstalt einen Interessenten für das veraltete Landflugzeug und bat das Reichsverkehrministerium, einem Verkauf der „Fokkerzelle“ und dem Tausch des „Aufklärers“ bzw. dem Verkauf zuzustimmen. Das Flugzeugwerk Raab-Katzenstein-GmbH Kassel hatte am Erwerb des Flugzeuges Interesse. Die Genehmigung ließ auf sich warten, da die Entente damals nicht erlaubt hatte, die Flugzeuge weiter zu veräußern. Die Überlassung ehemaliger Heeresflugzeuge an wissenschaftliche Institute, so der Minister, war

„auf besonders begründeten Antrag der Luftfahrt-Friedens-Kommission, und zwar nach eingeholter Entscheidung des Obersten Rates in Paris, unter Würdigung der angeführten Gründe kostenlos erfolgt. Die von der Interalliierten Luftüberwachungskommission bzw, ihrer Nachfolgerin, dem interalliierten Luftfahrt-Garantie-Komitee, auferlegten Verpflichtungen sahen u. a. auch das Verbot der Veräußerung dieser Flugzeuge an Dritte vor" (42).

Zusätzliche Schwierigkeiten bereitete der Wunsch der Anstalt, den aus dem Verkauf des Flugzeuges erzielten Erlös als Grundstock für den Erwerb eines Seeflugzeuges behal- 
ten zu dürfen. Der Verkehrsminister entsprach dieser Bitte nicht, sondern betonte, daß der Erlös dem Reich gehöre und an sein Ministerium abzuführen sei. Falls das Leichtflugzeug "Grasmücke“ erworben werde, gehöre dieses auch dem Reich.

Mielck reagierte daraufhin sehr betroffen, da die Anstalt, wie er sich ausdrückte, durch diese Entscheidung alles verlieren würde. Dennoch wurde sie nicht geändert, und der Vorgang ruhte bis Mai 1929. Im Sommer 1929 teilte die Anstalt mit, daß die Firma Raab-Katzenstein ihr Interesse am Erwerb des alten LVGC VI verloren habe, es aber der Anstalt gelungen sei, die komplizierten Verhandlungen wiederaufzunehmen. Raab-Katzenstein habe in Aussicht gestellt, daß man gegen einen Wertausgleich von 1000 RM und Übernahme der Transportkosten vielleicht doch bereit sei, ein neueres Flugzeug herzugeben. Mit so ungenauen Angaben gab sich der Minister nicht zufrieden und verlangte eine Feststellung des Wertes des angeblich unbrauchbar gewordenen Flugzeuges. Hier brechen die Überlieferungen ab. Hinweise dafür, daß der Tausch zustande kam und die Vogelzugsforschung per Flugzeug fortgeführt wurde, sind nicht ermittelt worden.

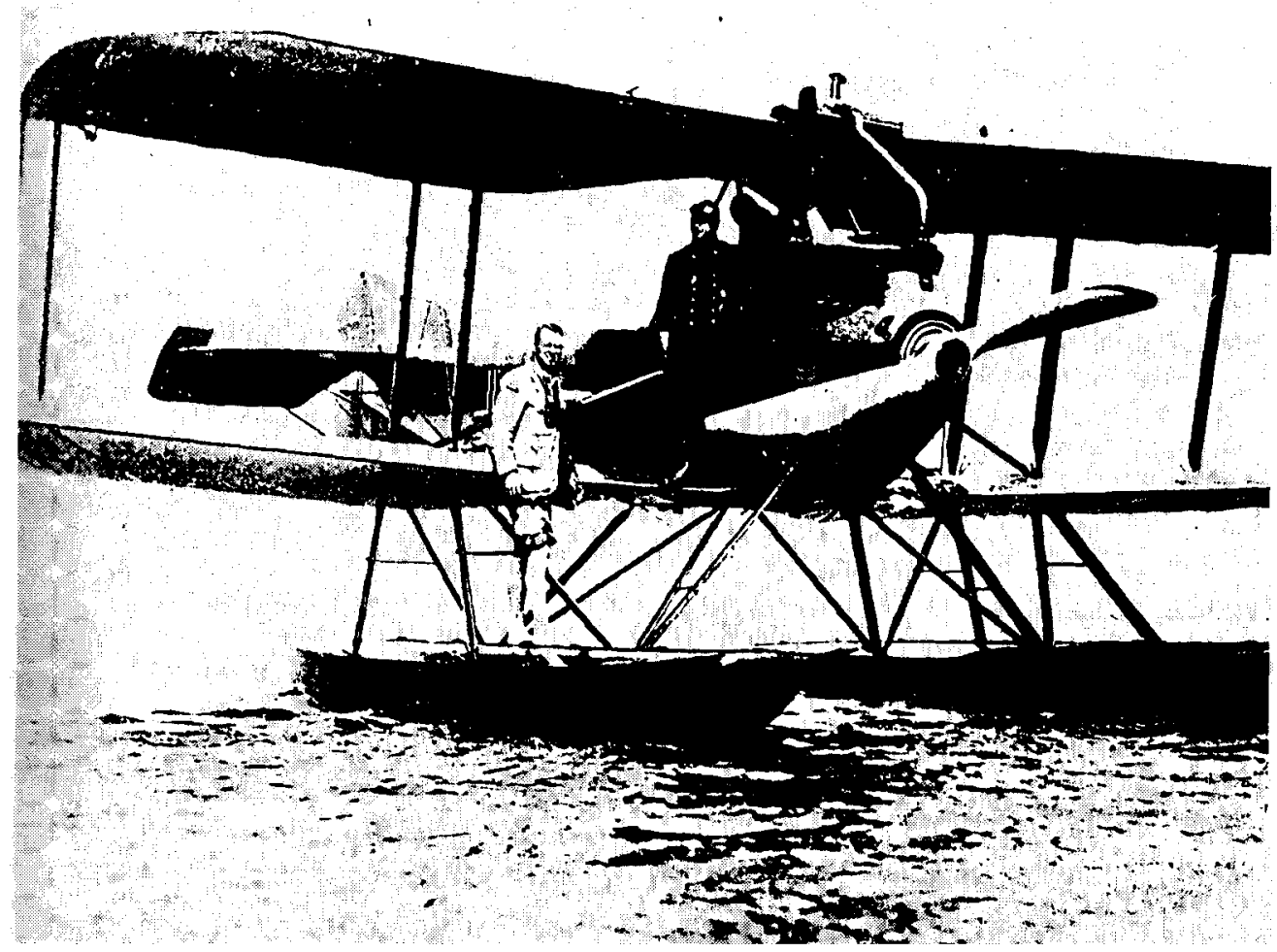

Abb. 36. Wasserflugzeug der Marine, Typ L.V.G., mit Dr. Weigold und Pilot, 1920. Der Erwerb solcher Flugzeuge wurde von der Biologischen Anstalt angestrebt. Archiv der Vogelwarte Helgoland. 